\title{
Numerical Study Comparing RANS and LES Approaches on a Circulation Control Airfoil
}

\author{
Christopher L. Rumsey* \\ NASA Langley Research Center, Hampton, VA 23681-2199 \\ Takafumi Nishino $^{\dagger}$ \\ NASA Ames Research Center, Moffett Field, CA 94035-1000
}

\begin{abstract}
A numerical study over a nominally two-dimensional circulation control airfoil is performed using a largeeddy simulation code and two Reynolds-averaged Navier-Stokes codes. Different Coanda jet blowing conditions are investigated. In addition to investigating the influence of grid density, a comparison is made between incompressible and compressible flow solvers. The incompressible equations are found to yield negligible differences from the compressible equations up to at least a jet exit Mach number of 0.64. The effects of different turbulence models are also studied. Models that do not account for streamline curvature effects tend to predict jet separation from the Coanda surface too late, and can produce non-physical solutions at high blowing rates. Three different turbulence models that account for streamline curvature are compared with each other and with large eddy simulation solutions. All three models are found to predict the Coanda jet separation location reasonably well, but one of the models predicts specific flow field details near the Coanda surface prior to separation much better than the other two. All Reynolds-averaged Navier-Stokes computations produce higher circulation than large eddy simulation computations, with different stagnation point location and greater flow acceleration around the nose onto the upper surface. The precise reasons for the higher circulation are not clear, although it is not solely a function of predicting the jet separation location correctly.
\end{abstract}

\section{Nomenclature}

$\begin{array}{llll}A & \text { Planform area } & P & \text { Production terms, Eqs. (2) and (8) } \\ a & \text { Speed of sound } & p & \text { Pressure } \\ C_{L} & \text { Section lift coefficient, } L /\left(q_{\infty} A\right) & q & \text { Dynamic pressure, } \rho U^{2} / 2 \\ C_{p} & \text { Pressure coefficient, }\left(p-p_{\infty}\right) / q_{\infty} & R e & \text { Reynolds number, } \rho U_{\infty} c / \mu \\ C_{r c} & \text { Constant for SSTRC model } & R_{i} & \text { Gradient Richardson number, Eq. (10) } \\ C_{\mu} & \text { Jet momentum coefficient, Eq. (11) } & r & \text { Radius of curvature } \\ c & \text { Airfoil chord length } & \tilde{r} & \text { Term in SARC model } \\ c_{b 1} & \text { Constant in SA model } & r^{*} & S / \Omega \\ c_{r 1}, c_{r 2}, c_{r 3} & \text { Constants in SARC model } & S & \text { Magnitude of strain, Eq. (5) } \\ c_{\mu}^{\prime} & \text { coefficient in EASM-ko model } & \tilde{S} & \text { Term in SA model } \\ D_{d i f f} & \text { Diffusion term in SA model } & S_{i j} & \text { Strain rate tensor } \\ D_{d i s s} & \text { Dissipation term in SA model } & t & \text { time } \\ \text { dist } & \text { Normal distance from the wall } / c & U & \text { Velocity } \\ F_{1} & \text { Function in SST and SSTRC models } & u, v, w & \text { Cartesian velocity components } \\ F_{4} & \text { Sensitization factor, Eq. (9) } & u_{j} & \text { Cartesian velocity component } \\ f_{r 1}, f_{t 2} & \text { Functions in SA model } & u_{\theta} & \text { Streamwise velocity } \\ h & \text { Slot height } & \frac{u_{i}^{\prime} u_{j}^{\prime}}{u_{\theta}^{\prime} w_{\theta}^{\prime}} & \text { Specific turbulent stress tensor component } \\ k & \text { Turbulent kinetic energy } & \text { Specific turbulent shear stress, Eq. (12) } \\ L & \text { Lift force } & W_{i j} & \text { Vorticity tensor } \\ M & \text { Mach number, } U / a & x, y, z & \text { Cartesian coordinates } \\ \dot{m} & \text { Mass flow rate } & x_{j} & \text { Cartesian coordinate }\end{array}$

\footnotetext{
* Senior Research Scientist, Computational AeroSciences Branch, Mail Stop 128, Associate Fellow AIAA.

${ }^{\dagger}$ Postdoctoral Fellow, NASA Advanced Supercomputing Division, Mail Stop T27B-1, Member AIAA.
} 


$\begin{array}{ll}\text { Greek: } & \\ \alpha & \text { Angle of attack (deg) } \\ \beta, \beta^{*} & \text { Constants in SST and SSTRC models } \\ \Delta s^{+} & \text {Streamwise spacing in wall units } \\ \Delta n^{+} & \text {Normal spacing in wall units } \\ \Delta b^{+} & \text {Spanwise spacing in wall units } \\ \gamma & \text { Constant in SST and SSTRC models } \\ \mu & \text { Coefficient of viscosity } \\ \mu_{t} & \text { Turbulent eddy viscosity } \\ \tilde{\nu} & \text { Turbulence variable in SA model } \\ \theta & \text { Angle (deg) around Coanda surface } \\ \rho & \text { Density } \\ \sigma_{k}, \sigma_{\omega}, \sigma_{\omega 2} & \text { Constants in SST and SSTRC models } \\ \tau & \text { Turbulence time scale } \\ \tau_{i j} & \text { Shear stress } \\ \Omega & \text { Magnitude of vorticity, Eq. (4) } \\ \omega & \text { Specific dissipation rate }\end{array}$

$\begin{array}{ll}\text { Subscript: } & \\ \text { inlet } & \text { Plenum inlet condition } \\ j & \text { Jet condition } \\ \text { max } & \text { Maximum condition } \\ \text { mean } & \text { Mean condition } \\ \text { ref } & \text { Reference }(\infty) \text { condition } \\ \text { sep } & \text { Jet separation location } \\ \infty & \text { Free-stream quantity }\end{array}$

\section{Introduction}

Circulation control can dramatically enhance the lift of airfoils and wings. By blowing a jet of air along an airfoil surface near its curved trailing edge, separation can be delayed because of the Coanda effect (which causes the jet to "stick" to the curved surface). See Fig. 1. Many computational studies have been done for circulation control airfoils; for example, see Refs. 1-9. However, in general most efforts have only attained limited success. In particular, many Reynolds-averaged Navier-Stokes (RANS) models can do reasonably well for low blowing conditions, but at higher blowing rates they tend to predict jet separation too late. In fact, sometimes the computed jet wraps un-physically too far onto the airfoil's lower surface, or even completely around the airfoil.

There are many difficulties associated with validating codes, methods, and models on circulation control airfoils. Due to the typically very narrow blowing-slot openings, the near-wall region of circulation control airfoil experiments can be very difficult to measure. In particular, it is important to know the jet exit conditions very accurately, so that the CFD can apply the same boundary conditions. The behavior of the jet can be very sensitive to the exit conditions. The integral quantity jet momentum coefficient, typically defined from experiment based on total mass flow rate and derived jet exit conditions, may be insufficient information for the purpose of CFD validation because of possible nonuniform blowing across the entire airfoil span and errors from the isentropic flow assumption. ${ }^{10}$ It is also particularly difficult to maintain/guarantee two-dimensionality in the wind tunnel flowfield at strong blowing conditions. Furthermore, three-dimensional vortical structures in the wind tunnel due to interaction with the side walls cause a net downwash (or effective negative angle of attack) that increases in magnitude with increasing blowing. Some 3-D RANS studies that included side walls ${ }^{2,10,11}$ have demonstrated this effect. The effect of this downwash can be difficult to accurately account for when performing 2-D CFD, especially when also attempting to account for the upper and lower tunnel walls. To date, 3-D LES computations have typically lacked the resources for attaining sufficient grid density to adequately resolve the side-wall vortical structures.

Of all RANS models applied to circulation control airfoils, arguably the most successful to date have incorporated some modeling of curvature effects, which can be significant in circulation control cases near the trailing edge Coanda surface. For example, the Spalart-Allmaras for Rotation and Curvature (SARC) model ${ }^{12}$ (see Swanson and Rumsey ${ }^{1}$ ) and a full Reynolds stress model (see Slomski et al ${ }^{13}$ ) tended to yield better results compared to experiment than other RANS models like Spalart-Allmaras (SA) ${ }^{14}$ or Menter's shear-stress transport (SST) $k-\omega,{ }^{15}$ which do not directly account for curvature. However, even curvature-corrected models have not done particularly well at very strong blowing conditions ${ }^{1}$ they still tend to yield too high lift compared with experiment.

Recently, LES computations have also been applied to circulation control flows. There has been some success at low blowing conditions, ${ }^{16-19}$ but at higher blowing rates LES has not been as successful. ${ }^{20}$ The lack of better overall success for LES to date may be due to insufficient computational resources. Since computational capacity changes very rapidly, this avenue of pursuit is being continued.

An on-going collaborative experiment at NASA Langley and Georgia Tech has been studying the flow around a circulation control airfoil designed at the Georgia Tech Research Institute (GTRI). ${ }^{21}$ Because only limited experimental 
data specifically for the purpose of CFD validation have been obtained to date for this model (see, e.g., Allan et al. ${ }^{10}$ ), this paper will focus on making comparisons between RANS and LES for flow over the GTRI model, with the intent of discerning key differences between the methods. The focus is to employ the methods on identical grids and matching boundary conditions at zero angle-of-attack, including the top and bottom walls. Three-dimensional effects due to side-walls are neglected, although the LES includes 3-D flowfield structures. We would like to answer the question: In what ways do the 2-D RANS and spanwise-averaged LES methods differ? Attempting to answer this question involves determining the influence of grid density, code, and turbulence modeling. A curvature correction for SST (from Hellsten ${ }^{22}$ and Mani et al. ${ }^{23}$ ), that has not been applied to circulation control airfoils before, is also examined. Eventually, it is hoped that LES may be used to improve RANS turbulence models for these kinds of flowfields.

This paper is organized as follows. After a brief description of the RANS and LES computer codes employed for this effort, the grid and test cases are described. Then, in the Results section, four areas of focus are discussed: (a) a grid and code sensitivity study, (b) comparisons between compressible and incompressible RANS solutions, (c) the effects of turbulence models and curvature corrections for a case with high blowing, and (d) comparisons between RANS and LES. Finally, conclusions are drawn.

\section{Numerical Methods and Turbulence Models}

The RANS computer codes employed for this study were FUN3D ${ }^{24}$ and CFL3D. ${ }^{25}$ FUN3D is an unstructured finite volume upwind-biased node-centered code, and CFL3D is a multiblock structured finite volume upwind-biased cell-centered code. Both solve the compressible RANS equations and are nominally second order spatially accurate.

FUN3D solves the equations on mixed element grids, including tetrahedra, pyramids, prisms, and hexahedra and also has a two-dimensional path for triangular and quadrilateral grids. It employs an implicit upwind algorithm in which the inviscid fluxes are obtained with the flux difference splitting scheme of Roe. ${ }^{26}$ For second-order accuracy, interface values are obtained by extrapolation of the control volume centroidal values, based on gradients computed at the mesh vertices using an unweighted least-squares technique. The solution at each time-step is updated with a backward Euler time-differencing scheme. At each time step, the linear system of equations is approximately solved with a multi-color point-implicit procedure. Local time-step scaling is employed to accelerate convergence to steadystate. For all the applications in this paper, FUN3D solves the turbulence equations with a first-order advection scheme.

In CFL3D, the convective term is approximated with third-order upwind-biased spatial differencing, and the viscous terms are discretized with second-order central differencing. The flux difference-splitting method of $\operatorname{Roe}^{26}$ is employed to obtain fluxes at the cell faces. Advancement in time is accomplished via backward Euler, with an implicit approximate factorization method. The turbulence equations are solved with a first-order advection scheme.

The LES code employed is CDP, an incompressible Navier-Stokes code developed at the Center for Turbulence Research (CTR) at Stanford University. ${ }^{27}$ CDP is a finite volume unstructured flow solver with second order spatial accuracy. It is based on the least-squares pressure gradient reconstruction of Mahesh et al. ${ }^{28}$ for hybrid unstructured grids. The methodology is nearly energy conserving in the inviscid limit. CDP uses central differencing and does not introduce any numerical dissipation or smoothing. The necessary dissipation comes solely through the subgrid-scale model. The subgrid-scale stresses in the CDP are modeled with the dynamic Smagorinsky model. ${ }^{29}$

The RANS turbulence models SA ${ }^{14}$ and $\mathrm{SST}^{15}$ and the LES dynamic Smagorinsky model ${ }^{29}$ are standard and will not be described here. Details can be found in their respective references. However, a brief discussion will be given for the less standard models SARC, EASM-ko, and SSTRC.

In the SARC model, ${ }^{12}$ the production term of the SA model is modified. In the original model,

$$
\frac{\partial \tilde{\nu}}{\partial t}+u_{j} \frac{\partial \tilde{\nu}}{\partial x_{j}}=P+D_{d i f f}+D_{d i s s}
$$

where $\tilde{\nu}$ is related to the kinematic eddy viscosity, $P=c_{b 1}\left(1-f_{t 2}\right) \tilde{S} \tilde{\nu}$, and $\tilde{S}$ is a function of the magnitude of the vorticity. All the terms are defined in the original SA reference. ${ }^{14}$ In the SARC modification,

$$
P=c_{b 1}\left(f_{r 1}-f_{t 2}\right) \tilde{S} \tilde{\nu}
$$

where

$$
f_{r 1}=\left(1+c_{r 1}\right) \frac{2 r^{*}}{1+r^{*}}\left[1-c_{r 3} \tan ^{-1}\left(c_{r 2} \tilde{r}\right)\right]-c_{r 1}
$$

with $r^{*}=S / \Omega$, and

$$
|\Omega|=\sqrt{2 W_{i j} W_{i j}},
$$




$$
|S|=\sqrt{2 S_{i j} S_{i j}}
$$

and $W_{i j}=\left(\partial u_{i} / \partial x_{j}-\partial u_{j} / \partial x_{i}\right) / 2$ is the vorticity tensor and $S_{i j}=\left(\partial u_{i} / \partial x_{j}+\partial u_{j} / \partial x_{i}\right) / 2$ is the strain-rate tensor. The function $\tilde{r}$ depends on the Lagrangian derivative of the strain-rate tensor (see original reference), and the constants are taken to be $c_{r 1}=1, c_{r 2}=12$, and $c_{r 3}=1$.

The EASM-ko model ${ }^{30}$ is an explicit algebraic stress model in $k-\omega$ formulation. In this model, the turbulent eddy viscosity $\mu_{t}$ is given by $\mu_{t}=c_{\mu}^{\prime} \rho k \tau$, where $\tau=1 / \omega$ for the $k-\omega$ version, and $c_{\mu}^{\prime}$ is a variable coefficient obtained through the solution of a cubic equation. This model makes use of a non-linear constitutive relation rather than the Boussinesq model. As discussed in Rumsey et al., ${ }^{31}$ because EASM formulations are derived directly from the Reynolds stress model, they retain some of the invariance properties of the full differential form even though the assumption of anisotropy equilibrium in the Cartesian frame of reference is not strictly correct for curved flows. A curvature corrected form of EASM was derived, but curved flow results were very similar to those predicted by the standard form of the model. Because the standard model is more robust than the curvature corrected version, only EASM-ko (the standard model) was used in the current work.

SSTRC is Hellsten's curvature correction ${ }^{22}$ to the standard SST model. In SSTRC, the destruction term in the $\omega$-equation is multiplied by a curvature sensitization factor $F_{4}$, which is a function of the local flow curvature. The equations are:

$$
\begin{gathered}
\rho \frac{\partial k}{\partial t}+\rho u_{j} \frac{\partial k}{\partial x_{j}}=P-\beta^{*} \rho k \omega+\frac{\partial}{\partial x_{j}}\left[\left(\mu+\frac{\mu_{t}}{\sigma_{k}}\right) \frac{\partial k}{\partial x_{j}}\right] \\
\rho \frac{\partial \omega}{\partial t}+\rho u_{j} \frac{\partial \omega}{\partial x_{j}}=\frac{\gamma \rho}{\mu_{t}} P-F_{4} \beta \rho \omega^{2}+\frac{\partial}{\partial x_{j}}\left[\left(\mu+\frac{\mu_{t}}{\sigma_{\omega}}\right) \frac{\partial \omega}{\partial x_{j}}\right]+2 \rho \frac{1-F_{1}}{\sigma_{\omega 2} \omega} \frac{\partial k}{\partial x_{j}} \frac{\partial \omega}{\partial x_{j}}
\end{gathered}
$$

where the turbulence production term is

$$
P=\tau_{i j} \frac{\partial u_{i}}{\partial x_{j}}
$$

The sensitization factor is given by

$$
F_{4}=\frac{1}{1+C_{r c} R_{i}} .
$$

The curvature sensitization factor $F_{4}$ is a local formulation that is independent of the coordinate system and based on Hellsten's approximation to the gradient Richardson number:

$$
R_{i}=\frac{|\Omega|}{|S|}\left(\frac{|\Omega|}{|S|}-1\right)
$$

This gradient Richardson number is easily computed, and is independent of coordinate system and grid topology. Near-wall convex curvature yields $F_{4}$ levels below 1, which decreases $\omega$-destruction and in turn increases $\omega$. The near-wall eddy viscosity decreases as a result. Therefore, usage of the correction coefficient $F_{4}$ weakens the turbulent boundary layer around convex curved surfaces, which creates a greater tendency to separate.

Hellsten originally recommended $C_{r c}=3.6$, but this value was found to diffuse the jet excessively in some applications. Mani et al. ${ }^{23}$ recommended a value of $C_{r c}=1.4$ for cases involving ground-jet interactions. This value is also used for all results here. See the original references for details concerning other terms in the equations.

\section{Description of Grid and Test Cases}

A near view of the 2-D grid (with every other gridpoint removed) is shown in Fig. 2. This figure also shows the geometry of the airfoil, including the dual-chambered plenum. The earlier sketch of Fig. 1 showed the geometry near the Coanda surface (note that the lower surface included a slot for blowing, but it was closed for the current study). Although not shown, the top and bottom tunnel walls were located at $z= \pm 0.508 \mathrm{~m}(z / c= \pm 2.327)$. A wavy transition strip was located near the lower surface leading edge (for details, see Nishino et al. ${ }^{17}$ ). The airfoil chord was $c=0.2183 \mathrm{~m}$. The jet slot height was $h=0.000503 \mathrm{~m}(h / c=0.0023)$. The radius of the Coanda surface was $r=0.02066 \mathrm{~m}(r / c=0.09463)$.

The fine grid employed for the LES computations had approximately 116 million grid points. It had a spanwise ( $y$-direction) extent of $0.014 \mathrm{~m}$ (or $y / c=0.0641$ ), with 256 points in that direction and periodic boundary conditions 
at the side boundaries. For the lowest jet blowing condition, the coarsest grid resolution (in wall units) over the Coanda surface was approximately $\Delta s^{+} \approx 42, \Delta n^{+} \approx 0.6, \Delta b^{+} \approx 25$, in the streamwise, wall-normal, and spanwise directions, respectively. Note that the resolution in wall units reported in Table 1 of Nishino et al. ${ }^{17}$ was not correct. The subgrid-scale eddy viscosity in the attached jet region (i.e., before the separation of the jet from the Coanda surface) was up to about 5 times larger than the molecular viscosity. For the higher jet blowing condition, the coarsest resolution was approximately $\Delta s^{+} \approx 60, \Delta n^{+} \approx 0.8, \Delta b^{+} \approx 36$, and the subgrid-scale eddy viscosity in the attached jet region was up to about 10 times larger than the molecular viscosity. The grid included the tunnel top and bottom walls, and also modeled the two inner plenum chambers as well as the wavy transition strip on the lower surface near the leading edge. The fine grid used for the RANS computations was the same, but was solved two-dimensionally using 451,400 grid cells in one spanwise row. It is important to note that for the 2-D RANS computations, the wavy strip (described in detail in Nishino et al. ${ }^{17}$ ), is simply a small rectangular bump located near $x / c=0.021$ with height $0.00256 c$ and length $0.01368 c$. The grid was originally constructed as a multi-zone grid with 73 zones. For use with FUN3D, a single zone consisting of hexahedral elements was created from the original grid by removing all duplicate points at the zone interfaces.

The free-stream flow conditions were: $M=0.099$, Re $=2.24 \times 10^{6}$ per $\mathrm{m}$, or Re $=488,992$ per chord. The RANS computations were run in steady-state mode, whereas the LES computations were run time-accurately and averaged to obtain statistically steady solutions, as described in Nishino et al. ${ }^{17}$ Because the simulations included wind tunnel walls, no angle of attack corrections were applied to any cases; all were run at $\alpha=0^{\circ}$. Viscous wall boundary conditions were applied on all surfaces of the airfoil, including the interior plenum. The only exception was the left-most face of the interior-most plenum, at which a velocity and density were specified (this face had a height of $0.01261 \mathrm{~m}$ ). The top and bottom tunnel walls were treated as inviscid surfaces. The upstream inflow plane (located at $x / c=-3.621$ ) had a farfield Riemann invariant boundary condition, and the downstream outflow plane (located at $x / c=10.005$ ) had a specified back pressure $p / p_{\text {ref }}=1.0$.

The various plenum boundary conditions employed are listed in Table 1. Conditions were chosen to match the mass flow rate, with total temperature at inflow of $295 \mathrm{~K}$. The jet momentum coefficient is defined as:

$$
C_{\mu}=\frac{\dot{m}_{j} U_{j, m e a n}}{q_{\text {ref }} A}
$$

where $\dot{m}_{j}$ is the mass flow rate at the jet exit and $U_{j, \text { mean }}$ is the mean jet velocity at the jet exit. Note that the specific conditions for compressible and incompressible boundary conditions at the inlet for the RANS and the LES needed to be somewhat different in order to achieve a similar velocity at the jet exit. The incompressible RANS computations in this paper used the (A) conditions; however, the difference between results using (A) and (B) conditions was fairly small. The reference velocity was $U_{r e f}=34 \mathrm{~m} / \mathrm{s}$. The reference speed of sound was $a_{r e f}=344 \mathrm{~m} / \mathrm{s}$ and the reference density was $\rho_{\text {ref }}=1.2 \mathrm{~kg} / \mathrm{m}^{3}$. Most comparisons were performed for the two lowest blowing conditions $\left(M_{j} \approx 0.39\right.$ and 0.64$)$. Only a few compressible RANS computations (and no LES) were performed at the highest blowing rate of $M_{j} \approx 0.90$, in order to demonstrate the effect that the various turbulence models have at that high blowing rate.

It is recognized that the local Mach number of the flow near the jet exit can exceed levels for which incompressible flow assumptions are considered valid. However, at least for the two lower blowing cases, it was felt that the high-

Mach-number regions were limited to a fairly small area so that use of the incompressible LES code was justified. ${ }^{17}$ As will be shown below, FUN3D was run both in compressible and incompressible modes and its results were compared in order to quantify the influence of solving the incompressible equations and justify their use for these flows.

\section{Results}

A list of the CFD computations performed is provided in Table 2. The table includes computed lift coefficients and jet separation angle $\left(\theta_{s e p}\right)$, as defined in Fig. 1. Note that the $M_{j}=0.39$ jet separation angle for the LES listed here is slightly different from that given in Nishino et al. ${ }^{18}$ because here we are accounting for the very thin region of mean reverse flow near the body that occurs near the jet separation point. In other words, the separation angle for all results in this paper is defined as the location where wall skin friction goes to zero in the time-averaged flow field. In the "extra-fine" grid used for one of the LES computations, the number of tangential cells around the Coanda surface was doubled (from 800 to 1600). All other aspects of the grid remained the same as the fine grid. On the other hand, the "medium" grid level used for the CFL3D grid-independence studies consisted of every other point removed from the fine grid in each coordinate direction.

Fig. 3 shows time-averaged surface pressure coefficients from the LES computations, demonstrating that - other 
Table 1. Summary of Coanda blowing conditions

\begin{tabular}{lcc}
\hline conditions per unit span & $U_{\text {inlet }}, \mathrm{m} / \mathrm{s}$ & $\rho_{\text {inlet }}, \mathrm{kg} / \mathrm{m}^{3}$ \\
\hline$\dot{m}=0.0636 \mathrm{~kg} /(\mathrm{m} \mathrm{s})\left(C_{\mu} \approx 0.044, M_{j} \approx 0.39, U_{j, \text { max }} \approx 130 \mathrm{~m} / \mathrm{s}\right)$ & & \\
compressible RANS & 3.925 & 1.285 \\
incompressible RANS (A) & 4.268 & 1.182 \\
incompressible RANS (B) & 4.203 & 1.2 \\
incompressible LES & 4.203 & 1.2 \\
\hline$\dot{m}=0.1048 \mathrm{~kg} /(\mathrm{m} \mathrm{s})\left(C_{\mu} \approx 0.120, M_{j} \approx 0.64, U_{j, \text { max }} \approx 210 \mathrm{~m} / \mathrm{s}\right)$ & \\
compressible RANS & 5.703 & 1.457 \\
incompressible RANS $(\mathrm{A})$ & 7.126 & 1.166 \\
incompressible RANS $(\mathrm{B})$ & 6.924 & 1.2 \\
incompressible LES & 6.924 & 1.2 \\
\hline$\dot{m}=0.1403 \mathrm{~kg} /(\mathrm{m} \mathrm{s})\left(C_{\mu} \approx 0.215, M_{j} \approx 0.90, U_{j, \max } \approx 300 \mathrm{~m} / \mathrm{s}\right)$ & & \\
compressible RANS & 6.248 & 1.781 \\
\hline
\end{tabular}

than in the immediate region of the wavy transition strip - the results were essentially statistically two-dimensional (see also Nishino et al. ${ }^{17}$ ). Therefore, direct comparisons between spanwise-averaged LES and 2-D RANS were possible.

\section{A. Grid and Code Sensitivity Study}

LES computations were performed for the $M_{j}=0.64$ case using both the fine grid (approximately 116 million total grid points) and the extra fine grid with double the number of tangential cells around the Coanda surface (approximately 175 million total grid points). Results were very nearly the same. Visualizations of the flow structures around the Coanda surface as well as averaged surface pressure coefficients are shown in Fig. 4. As described in Nishino et al., ${ }^{17}$ a number of hairpin-like flow structures were observed in the LES around the mixing layer of the high-speed jet flow and the low-speed external flow. Here, these flow structures appeared to be similar between the two grids.

Many 2-D RANS computations were performed on both the fine grid (451,400 grid cells) as well as on the medium grid with every other point removed (112,850 grid cells). Furthermore, the two codes FUN3D and CFL3D were run on the same fine grid using the common SA, SST, and SSTRC turbulence models as a code-independence check. FUN3D did not have the ability to run the SARC or EASM-ko turbulence models, but these were run with CFL3D on the two grid sizes. Results are tabulated in Table 2, and surface pressure coefficients are shown in Fig. 5. For the most part, results were nearly the same on the two grid sizes and with the two codes. (However, note that EASM-ko did not produce a steady-state solution at $M_{j}=0.39$ on the medium grid, so only the fine grid result is given.) Two exceptions to this were the SA and SST models on the $M_{j}=0.90$ case. These particular solutions were non-physical and not well-converged: the SA model allowed the jet to completely wrap around the airfoil, and the SST model allowed the jet to stick to the Coanda surface all the way to the lower surface, so that the jet faced forward into the oncoming stream. In the $c_{p}$ plots, this non-physical behavior shows up as a large "kink" or "step" in the lower surface pressure coefficient between $x / c=0.90$ and 1.0. This behavior was consistent between codes and occurred on both fine and medium grids.

Overall, the differences between the turbulence models were much greater than the differences due to grid or code. This fact is important, because it makes it possible to draw conclusions about the behavior of the turbulence models with some degree of confidence that discretization errors and code bias are probably not playing a significant part. As seen in Table 2, the effect of grid/code on lift coefficient and jet separation location were also minimal.

\section{B. Comparisons Between Compressible and Incompressible RANS Solutions}

For even moderate blowing conditions, the jet behaves compressibly near the jet exit. Nonetheless, researchers have employed both incompressible and compressible CFD codes to circulation control airfoil flows, but until now the impact of the type of solver has not been explored. It can be argued that the compressible region is very localized for many blowing rates, and hence the use of incompressible equations may not have much negative consequence for the 
Table 2. Summary of computations performed

\begin{tabular}{lcccccc}
\hline Method & $M_{j}$ & Code & Grids & Turbulence model & $C_{L}$ & Jet separ. $\left(\theta_{\text {sep }}\right)$ \\
\hline Incompressible LES & 0.39 & CDP & fine & dynamic Smag & 1.36 & $67^{\circ}$ \\
& 0.64 & CDP & fine / extra-fine & dynamic Smag & $3.50 / 3.51$ & $95^{\circ} / 96^{\circ}$ \\
\hline Incompressible RANS & 0.39 & FUN3D & fine & SA & 1.85 & $73^{\circ}$ \\
& 0.64 & FUN3D & fine & SA & 4.67 & $107^{\circ}$ \\
\hline Compressible RANS & 0.39 & FUN3D & fine & SA & 1.84 & $72^{\circ}$ \\
& 0.39 & FUN3D & fine & SST & 1.67 & $68^{\circ}$ \\
& 0.39 & FUN3D & fine & SSTRC & 1.56 & $64^{\circ}$ \\
& 0.64 & FUN3D & fine & SA & 4.65 & $107^{\circ}$ \\
& 0.64 & FUN3D & fine & SST & 4.49 & $106^{\circ}$ \\
& 0.64 & FUN3D & fine & SSTRC & 3.93 & $95^{\circ}$ \\
& 0.90 & FUN3D & fine & SA & 4.91 & wrap \\
& 0.90 & FUN3D & fine & SST & 6.46 & $174^{\circ}$ \\
& 0.90 & FUN3D & fine & SSTRC & 6.69 & $117^{\circ}$ \\
& 0.39 & CFL3D & fine / med & SA & $1.86 / 1.82$ & $73^{\circ} / 73^{\circ}$ \\
& 0.39 & CFL3D & fine / med & SARC & $1.72 / 1.71$ & $68^{\circ} / 67^{\circ}$ \\
& 0.39 & CFL3D & fine / med & SST & $1.70 / 1.69$ & $69^{\circ} / 68^{\circ}$ \\
& 0.39 & CFL3D & fine / med & SSTRC & $1.59 / 1.57$ & $65^{\circ} / 64^{\circ}$ \\
& 0.39 & CFL3D & fine / med & EASM-ko & $1.70 /$ unst & $68^{\circ} / \mathrm{unst}^{\circ}$ \\
& 0.64 & CFL3D & fine / med & SA & $4.72 / 4.66$ & $108^{\circ} / 108^{\circ}$ \\
& 0.64 & CFL3D & fine / med & SARC & $4.04 / 4.02$ & $95^{\circ} / 95^{\circ}$ \\
& 0.64 & CFL3D & fine / med & SST & $4.42 / 4.40$ & $105^{\circ} / 103^{\circ}$ \\
0.64 & CFL3D & fine / med & SSTRC & $3.92 / 3.90$ & $95^{\circ} / 93^{\circ}$ \\
& 0.64 & CFL3D & fine / med & EASM-ko & $4.10 / 4.07$ & $97^{\circ} / 96^{\circ}$ \\
& 0.90 & CFL3D & fine / med & SA & $4.61 / 4.50$ & wrap $/ \mathrm{wrap}^{\circ}$ \\
& 0.90 & CFL3D & fine / med & SARC & $6.96 / 6.84$ & $112^{\circ} / 112^{\circ}$ \\
& 0.90 & CFL3D & fine / med & SST & $6.88 / 7.02$ & $169^{\circ} / 155^{\circ}$ \\
& 0.90 & CFL3D & fine / med & SSTRC & $6.79 / 6.69$ & $119^{\circ} / 118^{\circ}$ \\
& 0.90 & CFL3D & fine / med & EASM-ko & $6.74 / 6.71$ & $116^{\circ} / 115^{\circ}$ \\
\hline
\end{tabular}

7 of 29 
global flow field.

By using a single code (FUN3D) that has both incompressible and compressible capabilities, the impact is explored for the first time here. Figs. 6(a) and (b) show streamlines for the $M_{j}=0.64$ case, using FUN3D in incompressible and compressible mode, respectively. Fig. 6(c) shows the streamwise velocity $\left(u_{\theta}\right.$ nondimensionalized by the reference velocity) profile comparisons. Incompressible and compressible results were essentially the same, including the jet separation location. Although not shown, results for the $M_{j}=0.39$ case were even closer, as would be expected. The $M_{j}=0.90$ case produced non-physical results using the SA model, so did not provide any useful information. These results appear to justify the use of incompressible flow solvers (like the CDP code employed for LES computations), at least for blowing rates up to $M_{j}=0.64$.

\section{Effect of Turbulence Model and Curvature Correction for $\mathrm{M}_{\mathrm{j}}=\mathbf{0 . 9 0}$}

Results from Swanson et al. ${ }^{2}$ indicated that a rotation/curvature correction to the SA turbulence model can significantly improve results for circulation control cases. Furthermore, Swanson et al. showed that the SST model tended to produce poor solutions at higher blowing rates. Here, two other turbulence models that provide some level of sensitivity to flow curvature - EASM-ko and SSTRC - are also examined for the $M_{j}=0.90$ case. EASM models were also investigated previously for circulation control airfoils by Gross and Fasel..$^{9}$

Earlier, Fig. 5 showed surface pressure coefficients for all the RANS models on all three cases. The two cases that stood out (in a negative sense) were SA and SST at $M_{j}=0.90$. Figs. 7(a)-(e) show streamlines for the $M_{j}=0.90$ case, using all five RANS models. The jet in the SA result wrapped completely around the airfoil (Fig. 7(a)), and the jet in the SST result separated close to the end of the Coanda surface near $\theta=170^{\circ}$ (Fig. 7(b)). Neither of these models accounts for curvature. The three models that account for curvature yielded separation locations near $\theta \approx 110^{\circ}-120^{\circ}$. Based on other circulation control airfoil experiments (e.g., Novak et al. ${ }^{32}$ ), this separation location appears much more reasonable than that predicted by SA or SST.

\section{Comparisons Between RANS and LES Solutions}

The mean LES lift coefficients as a function of $C_{\mu}$ are compared with the steady 2-D RANS results in Fig. 8. Generally, the SARC, SSTRC, and EASM-ko results were within a few percent of each other at all blowing values. The SA and SST levels were higher at the $M_{j}=0.64$ condition. At the highest blowing condition, the SA wrap-around produced a very low $C_{L}$ value, while the SST (coincidentally) produced $C_{L}$ in agreement with SARC, SSTRC, and EASM-ko in spite of the fact that its jet separation angle was so much larger. The LES results were lower than the best of the other models by between 12 and $17 \%$.

\section{1. $M_{j}=0.39$ Case}

Fig. 9 shows surface pressure coefficients for the $M_{j}=0.39$ case. As discussed in Nishino et al., ${ }^{17}$ the LES yielded excellent agreement with (preliminary) experimental data at this blowing condition. The LES also agreed well with independent implicit LES computations of Madavan and Rogers ${ }^{19}$ (note that the latter computations were not direct numerical simulations, as implied by the paper's title). Here, all RANS results predicted more upper surface suction than the LES. The jet in the SA model result separated slightly later (by $5-6^{\circ}$ ) than LES, but all the other RANS models predicted the separation within $1-3^{\circ}$ of LES.

Both here and in Nishino et al. ${ }^{18} C_{p}$ results using SA were furthest from LES. Here, the SST, SARC, and EASMko were all about the same, and SSTRC was the closest to LES. Additional details are shown in Figs. 10 and 11. (In these figures, only the best RANS results SSTRC, SARC, and EASM-ko are shown.) The SSTRC and EASM-ko models both predicted a higher peak jet velocity and narrower jet width compared to LES, while the SARC model was much closer. In fact, SARC and LES velocity profiles were very similar prior to jet separation. In Fig. 11, the nondimensional turbulent quantity $\overline{u_{\theta}^{\prime} w_{\theta}^{\prime}}$ is given in a coordinate system aligned with the local near-wall flow and flow-normal directions, where

$$
\overline{u_{\theta}^{\prime} w_{\theta}^{\prime}}=-\frac{1}{2}\left(\overline{w^{\prime} w^{\prime}}-\overline{u^{\prime} u^{\prime}}\right) \sin (2 \theta)+\overline{u^{\prime} w^{\prime}} \cos (2 \theta)
$$

with $\overline{u^{\prime} u^{\prime}}, \overline{w^{\prime} w^{\prime}}$, and $\overline{u^{\prime} w^{\prime}}$ the Cartesian specific turbulent shear stress components. Note that the LES results included only the resolved component (i.e., the subgrid-scale contributions, which were fairly small in the attached jet region, were not included). On the whole, all RANS models overpredicted the $\overline{u_{\theta}^{\prime} w_{\theta}^{\prime}}$ peak magnitude close to the wall 
compared to LES. In the outer part of the jet, the SSTRC and EASM-ko models severely underpredicted the peak magnitude and extent, whereas the SARC model was closer in the regions prior to jet separation.

Comparing the streamlines around the back of the airfoil in Fig. 12, it can be seen that SSTRC yielded a bubble that was much too large compared to LES, and EASM-ko yielded a separation bubble that was very different in character from the LES. The SARC solution was very close to the LES solution, but the separation bubbles were slightly different in shape, and the SARC streamlines drove vertically downward further than for LES. Fig. 13 shows jet/wake profiles behind the airfoil. At the first position near the closure of the separation bubble, all the RANS models were fairly consistent with LES, but further downstream there were bigger differences. The RANS models all almost completely dissipated the very weak jet, and exhibited more wake-like behavior than LES. With these differences in bubble size/position and jet/wake behavior and position, the RANS solutions had a resulting larger overall circulation than LES. Thus, as shown in Fig. 14, the RANS stagnation point near the airfoil leading edge was further downstream (note that the region near the trip is not shown in the LES solution because the 3-D spanwise waviness of the trip itself precluded spanwise averaging in this area). Although not shown, the other RANS models were similar to SARC. Therefore the RANS flow accelerated more around the nose. Boundary layer profiles on the upper and lower surfaces near $x / c=0.8$ are shown in Fig. 15. Both upper and lower surfaces were turbulent at these locations. Because the stagnation point locations did not agree, the edge velocities for RANS were different than for LES, as expected.

\section{2. $M_{j}=0.64$ Case}

The $M_{j}=0.64$ surface pressure coefficients and Coanda profile results are shown in Figs. 16, 17, and 18. Similar to the lower blowing case, here the SA and SST yielded the worst agreement with LES. The SA and SST produced similar jet separation locations between 105-108 ${ }^{\circ}$, whereas LES, SSTRC, SARC, and EASM-ko all separated earlier, near $95-97^{\circ}$. Among the RANS models that accounted for curvature, all produced very similar $c_{p}$ distributions, but none agreed with LES. Again, SARC came the closest to agreeing with the velocity and $\overline{u_{\theta}^{\prime} w_{\theta}^{\prime}}$ profiles from LES prior to separation.

The $M_{j}=0.64$ blowing case was different in character than the $M_{j}=0.39$ case, because there was no longer a large separation bubble directly next to the underside of the separating jet, but rather a much smaller one further around, nearer to the bottom of the Coanda surface. (As was seen in Fig. 7, at the even stronger blowing with $M_{j}=0.90$ this separation bubble went away completely.) Fig. 19 shows details of the flowfields near the trailing edge. The separation bubble was slightly smaller for SARC than for LES, but SSTRC and EASM-ko agreed well with LES in this regard. In spite of the fact that the RANS solutions separated at about the same location as the LES solution, the RANS jets moved downward further vertically than LES downstream. As seen in Fig. 20, in this higher blowing case the jet remained fairly strong post-separation, and in terms of peak velocity and spreading rate, the SSTRC and EASM-ko both did a reasonably good job predicting it. However, the SARC model dissipated the jet too quickly. This is a known problem with the SA model itself, ${ }^{33}$ and the problem no doubt carries over to the SARC variant. Again, all RANS models produced more circulation than LES. As seen in Fig. 21, the leading edge stagnation point for the RANS model was again located further aft on the lower surface, causing higher velocities as the flow accelerated onto the upper surface (although not shown, the leading edge behavior of SSTRC and EASM-ko were similar to SARC). Boundary layer profiles on the upper and lower surfaces near $x / c=0.8$ in Fig. 22 indicate that both upper and lower surfaces were turbulent at these locations. Again, because the stagnation point locations did not agree, the edge velocities for RANS were different than for LES.

\section{Discussion and Conclusions}

In past studies, it has been generally assumed that if one could capture the correct jet separation location from the Coanda surface of circulation control airfoils, then the simulation would yield accurate airfoil forces and pressure distributions. Many "standard" turbulence models in earlier studies tended to predict jet separation too late, consequently yielding lift predictions that were too high (compared to experiment) by a significant amount. Here, although detailed experimental data (including measurements of jet boundary conditions) for the particular configuration being studied have yet to be completed, we have compared 2-D RANS computations using various turbulence models with 3-D LES. We have demonstrated that turbulence models that account for curvature can produce jet separation locations that agree very well with LES. Three different models - SSTRC, SARC, and EASM-ko - all performed about the same in terms of the jet separation location and surface pressure coefficient predictions. However, the SARC model yielded much better detailed agreement in terms of velocity and turbulence profiles over the Coanda surface compared to LES. Past studies (e.g., Swanson and Rumsey, ${ }^{1}$ Pfingsten et al. ${ }^{7}$ ) have also shown the SARC model to be reasonably good for 
these types of flows.

Yet, in spite of agreeing fairly well for many details of the flowfield over the Coanda surface, the best RANS models still produced larger airfoil circulation (higher lift) than LES, by between about 12 and 17\%. The specific reasons for the larger circulation have not been determined yet. Some possibilities include: (a) differences in the shape of the separation bubble underneath the jet separation and the direction and location of the separated jet sheet, (b) inadequate spreading or dissipation of the downstream jet in the RANS models, and (c) insufficient grid resolution for LES, RANS (or both) in regions farther from the airfoil. Also, although SARC was the best at predicting the flow very near the Coanda surface, it was worse than the SSTRC and EASM-ko models in predicting the free-shear jet characteristics downstream in the $M_{j}=0.64$ case. The turbulence model must be able to accurately capture both near-wall curvature effects and free-shear planar jet decay for these problems. It appears that without a sharp trailing edge (Kutta condition), the jet behavior downstream can be extremely sensitive in these circulation control airfoil cases. And the airfoil circulation in turn appears to be very sensitive to small differences in jet behavior and location.

In terms of grid resolution, the RANS made use of one plane of the 3-D LES grid; this was very fine compared to grid sizes typically used for 2-D RANS in past studies. It was demonstrated that this grid size was fine enough to yield RANS solutions with very little differences from solutions on half the grid size in each coordinate direction. Two independent RANS codes also produced almost the same results. It is not known at this time whether the LES computations were adequately grid-converged. Best-practices for airfoil-type LES computations were followed within the available resource constraints. One LES computation required on the order of 2 months to complete using 256 processors. (Each fine grid RANS computation took on the order of several hours on 6 processors). A refinement of the grid in the region of the Coanda surface made little difference to the LES solution, but only the streamwise direction was refined due to resource constraints.

In all of the computations performed, care was taken to set the boundary conditions inside the jet plenum in order to match both the jet mass flow rate and the velocity profile at the jet exit. With this same starting condition at the jet exit for all codes, it was possible to confidently conclude that differences downstream were due to the turbulence modeling, and not due to other factors such as boundary condition influence.

As mentioned above, detailed experimental data for this configuration for the purpose of CFD validation is being acquired, but is not yet available. Preliminary comparisons between LES and experiment ${ }^{17}$ indicated near perfect agreement between LES and experiment at the lowest blowing condition, but poorer agreement at a higher blowing condition. Measured experimental jet boundary conditions at the slot exit will be required before drawing any firm conclusions, however. Also, it is well-known that interactions of the jet sheet with tunnel side walls cause roll-up vortices downstream, which induce a net downwash on the airfoil. This effect increases with increasing blowing rate. To date this downwash influence has not been accounted for in the LES computations.

In conclusion, this paper has highlighted some key differences between RANS and LES for circulation control airfoil flow. It was shown that use of an incompressible LES code was likely to be valid for this configuration for jet blowing up to at least $M_{j}=0.64$. This was demonstrated by using an incompressible and compressible version of the same RANS code, and showing essentially identical results. In other words, for these cases the small region near the jet exit where the local Mach number exceeded levels where the incompressible assumption is strictly valid did not affect the solution noticeably. Several RANS turbulence models were compared with each other and with LES. At very high blowing rates, the standard SA and SST models, which do not account for flow curvature effects, had a tendency to produce non-physical solutions, with SA somewhat worse than SST. Three different models that account for curvature - SSTRC, SARC, and EASM-ko - all behaved better, and were generally similar to each other overall. The behavior of SSTRC on a circulation control airfoil case has not been documented previously. All three models did a good job predicting the jet separation location. SARC agreed much better with LES in terms of Coanda profile details, but worse in terms of downstream jet dissipation and spreading. All RANS models produced higher circulation (higher lift) than LES, with different stagnation point location and greater flow acceleration around the nose onto the upper surface. The precise reasons for the higher circulation are not clear, although it is not solely a function of predicting the jet separation location correctly, as previously believed. A current hypothesis is that differences in the predicted character and location of the jet sheet after it separates from the airfoil are a significant contributing factor.

\section{Acknowledgments}

The first author would like to thank Ms. Shelly Jiang, who served as an intern at NASA Langley during summer 2009 and helped to implement and test the SSTRC model. The second author would like to thank Dr. Seonghyeon Hahn of Stanford University for providing the LES code. This work was funded by the Subsonic Fixed Wing Project of the Fundamental Aerodynamics Program. 


\section{References}

${ }^{1}$ Swanson, R. C. and Rumsey, C. L., "Computation of Circulation Control Airfoil Flows,” Computers \& Fluids, Vol. 38, 2009, pp. 1925-1942.

${ }^{2}$ Swanson, R. C., Rumsey, C. L., and Anders, S. G., "Progress Towards Computational Method for Circulation Control Airfoils," AIAA Paper 2005-0089, January 2005.

${ }^{3}$ Chang, P. A., Slomski, J. F., Marino, T., and Ebert, M. P., "Numerical Simulation of Two- and Three-Dimensional Circulation Control Problems," AIAA Paper 2005-0080, January 2005.

${ }^{4}$ Zacharos, A. and Kontis, K., "Numerical Studies on Active Flow Circulation Controlled Flap Concept for Aeronautical Applications," AIAA Paper 2004-2314, June-July 2004.

${ }^{5}$ Friedman, C., Arieli, R., and Levy, Y., “Numerical Investigation of Unsteady Circulation Control,” AIAA Paper 2007-3918, June 2007.

${ }^{6}$ Baker, W. J. and Patterson, E. G., "RANS CFD Simulation of a Circulation-Control Foil: Validation of Performance, Flow Field, and Wall Jet," AIAA Paper 2006-3010, June 2006.

${ }^{7}$ Pfingsten, K.-C., Jensch, C., Korber, K. W., and Radespiel, R., "Numerical Simulation of the Flow Around Circulation Control Airfoils," First CEAS European Air and Space Conference, September 2007, Berlin, Germany.

${ }^{8}$ Min, B.-Y., Lee, W., Englar, R., and Sankar, L., "Numerical Investigation of Circulation Control Airfoils," Journal of Aircraft, Vol. 46, No. 4, 2009, pp. 1403-1410.

${ }^{9}$ Gross, A. and Fasel, H. F., “CFD for Investigating Active Flow Control (Invited)," AIAA Paper 2008-4310, June 2008.

${ }^{10}$ Allan, B. G., Jones, G. S., and Lin, J. C., "Reynolds-Averaged Navier-Stokes Simulation of a 2D Circulation Control Wind Tunnel Experiment," 49th AIAA Aerospace Sciences Meeting, American Institute of Aeronautics and Astronautics, Reston, VA (submitted for publication).

${ }^{11}$ Nishino, T. and Shariff, K., "Numerical Study of Wind-Tunnel Sidewall Effects on Circulation Control Airfoil Flows," AIAA Journal, Vol. 48, No. 9, 2010, pp. 2123-2132.

${ }^{12}$ Shur, M. L., Strelets, M. K., Travin, A. K., and Spalart, P. R., "Turbulence Modeling in Rotating and Curved Channels: Assessing the Spalart-Shur Correction," AIAA Journal, Vol. 38, No. 5, 2000, pp. 784-792.

${ }^{13}$ Slomski, J. F., Gorski, J. J., Miller, R. W., and Marino, T. A., "Numerical Simulation of Circulation Control Airfoils as Affected by Different Turbulence Models," AIAA Paper 2002-0851, January 2002.

${ }^{14}$ Spalart, P. R. and Allmaras, S. R., “A One-Equation Turbulence Model for Aerodynamic Flows,” Recherche Aerospatiale, No. 1, 1994, pp. $5-21$.

${ }^{15}$ Menter, F. R., "Two-Equation Eddy-Viscosity Turbulence Models for Engineering Applications," AIAA Journal, Vol. 32, No. 8, 1994, pp. $1598-1605$.

${ }^{16}$ Hahn, S. and Shariff, K., "Large-Eddy Simulation of Flow Around a Circulation Control Airfoil," International Powered Lift Conference (IPLC 2008), Paper RaeS-566-8A2, July 2008.

${ }^{17}$ Nishino, T., Hahn, S., and Shariff, K., "Calculation of the Turbulent Characteristics of Flow Around a Circulation Control Airfoil Using LES (Invited),” AIAA Paper 2010-347, January 2010.

${ }^{18}$ Nishino, T., Hahn, S., and Shariff, K., "LES of High-Reynolds-Number Coanda Flow Separating From a Rounded Trailing Edge of a Circulation Control Airfoil," 8th International ERCOFTAC Symposium on Engineering Turbulence Modelling and Measurements, June 2010, Marseille, France.

${ }^{19}$ Madavan, N. K. and Rogers, M. M., "Direct Numerical Simulation of Flow Around a Circulation Control Airfoil," AIAA Paper 2010-4577, June-July 2010.

${ }^{20}$ Slomski, J. F., Chang, P. A., and Arunajatesan, S., "Large Eddy Simulation of a Circulation Control Airfoil," AIAA Paper 2006-3011, June 2006.

${ }^{21}$ Englar, R. J., Jones, G. S., Allan, B. G., and Lin, J. C., "2-D Circulation Control Airfoil Benchmark Experiments Intended for CFD Code Validation," AIAA Paper 2009-902, January 2009.

${ }^{22}$ Hellsten, A., "Some Improvements in Menter’s k- $\omega$ SST Turbulence Model," AIAA Paper 98-2554, June 1998.

${ }^{23}$ Mani, M., Ladd, J. A., and Bower, W. W., "Rotation and Curvature Correction Assessment for One- and Two-Equation Turbulence Models," Journal of Aircraft, Vol. 41, No. 2, 2004, pp. 268-273.

${ }^{24}$ Anderson, W. K. and Bonhaus, D. L., "An Implicit Upwind Algorithm for Computing Turbulent Flows on Unstructured Grids," Computers \& Fluids, Vol. 23, No. 1, 1994, pp. 1-21.

${ }^{25}$ Krist, S. L., Biedron, R. T., and Rumsey, C. L., “CFL3D User’s Manual,”, NASA TM 1998-208444, June 1998.

${ }^{26}$ Roe, P. L., "Approximate Riemann Solvers, Parameter Vectors, and Difference Schemes," Journal of Computational Physics, Vol. 43, 1981, pp. 357-372.

${ }^{27}$ Ham, F. and Iaccarino, G., "Energy Conservation in Collocated Discretization Schemes on Unstructured Meshes," Annual Research Briefs 2004, Center for Turbulence Research, Stanford University, 2004, pp. 3-14.

${ }^{28}$ Mahesh, K., Constantinescu, G., and Moin, P., "A Numerical Method for Large-Eddy Simulation in Complex Geometries," Journal of Computational Physics, Vol. 197, 2004, pp. 215-240.

${ }^{29}$ Lilly, D. K., "Proposed Modification of the Germano Subgrid-Scale Closure Method," Physics of Fluids A, Vol. 4, 1992, pp. $633-635$.

${ }^{30}$ Rumsey, C. L. and Gatski, T. B., "Summary of EASM Turbulence Models in CFL3D with Validation Test Cases," NASA/TM-2003-212431, June 2003

${ }^{31}$ Rumsey, C. L., Gatski, T. B., Anderson, W. K., and Nielsen, E. J., "Isolating Curvature Effects in Computing Wall-Bounded Turbulent Flows," International Journal of Heat and Fluid Flow, Vol. 22, 2001, pp. 573-582.

${ }^{32}$ Novak, C. J., Cornelius, K. C., and Roads, R. K., "Experimental Investigations of the Circular Wall Jet on a Circulation Control Airfoil," AIAA Paper 87-0155, January 1987.

${ }^{33}$ Bardina, J. E., Huang, P. G., and Coakley, T. J., “Turbulence Modeling Validation, Testing, and Development,” NASA TM 110446, April 1997. 


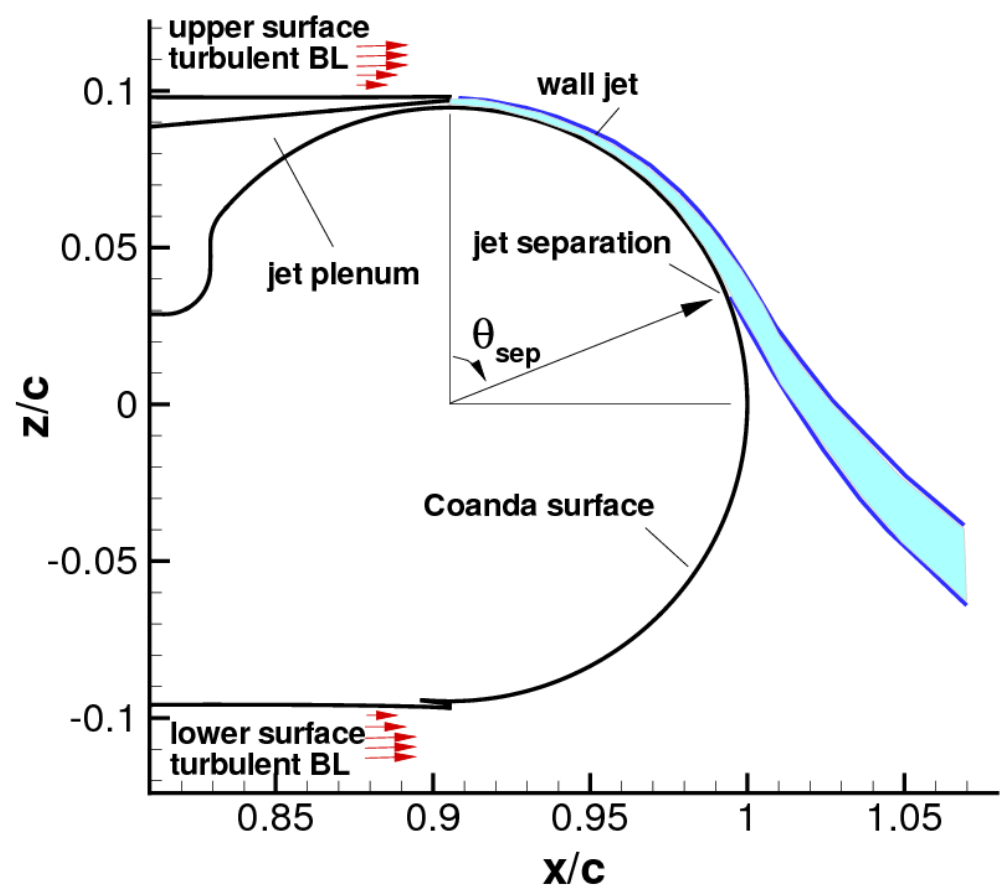

Figure 1. Sketch of Coanda flow.

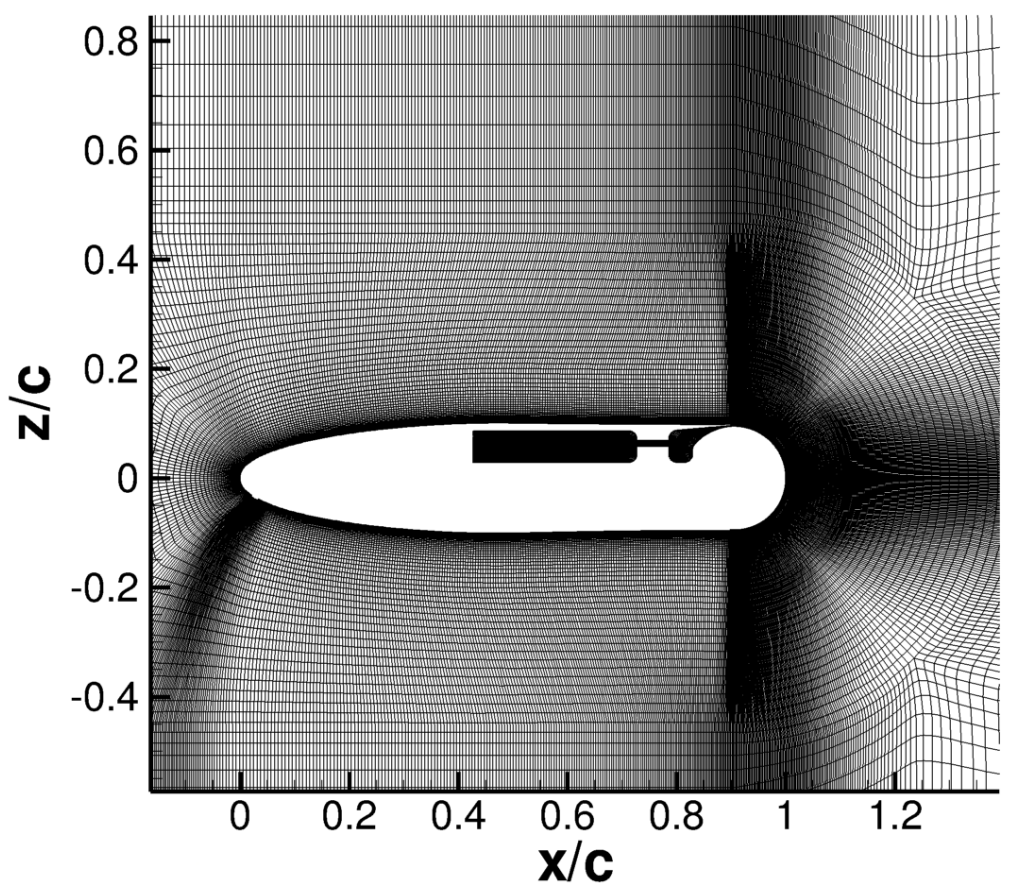

Figure 2. View of circulation control airfoil grid (with every other grid point removed). 


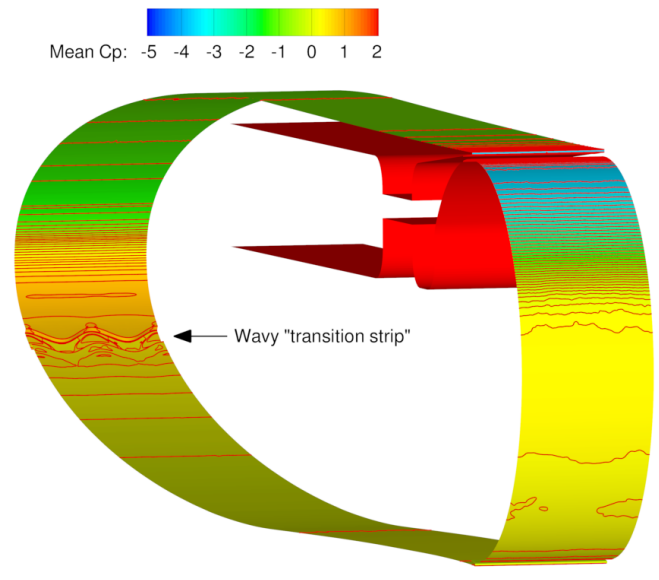

(a) $M_{j}=0.39$, overall view

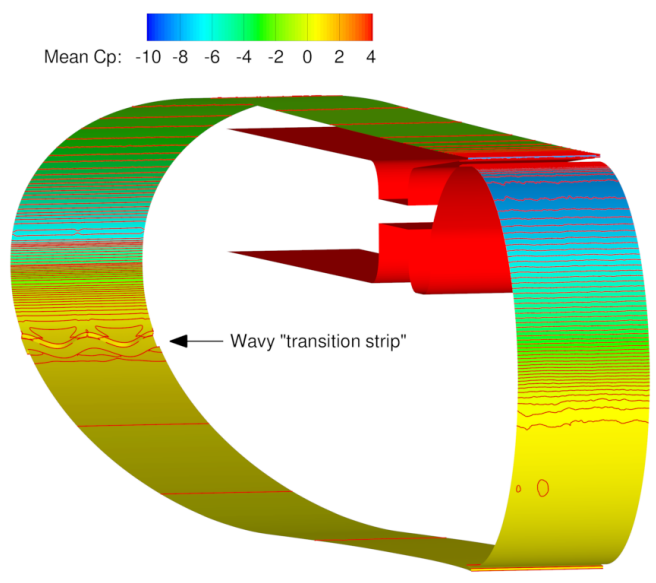

(c) $M_{j}=0.64$, overall view

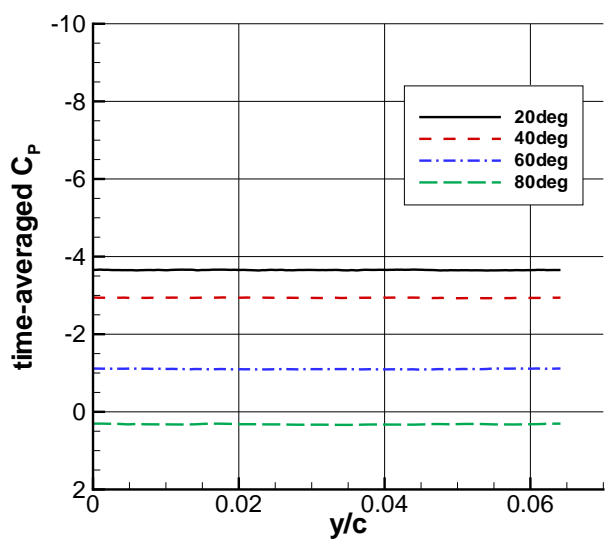

(b) $M_{j}=0.39$, spanwise details on upper Coanda surface

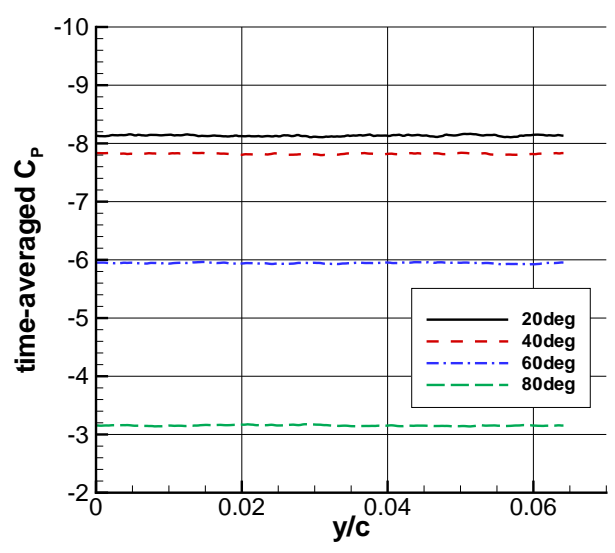

(d) $M_{j}=0.64$, spanwise details on upper Coanda surface

Figure 3. Time-averaged surface pressure coefficients from LES computations. 


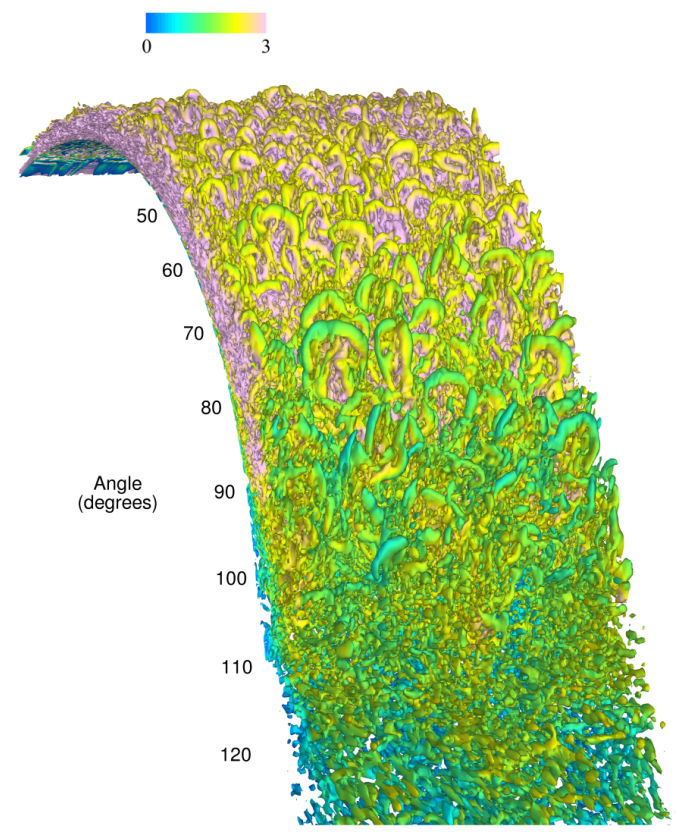

(a) Iso-surfaces of second invariant of velocity gradient tensor, colored by the magnitude of velocity $\left(u_{i} u_{i}\right)^{1 / 2} / U_{r e f}$, fine grid

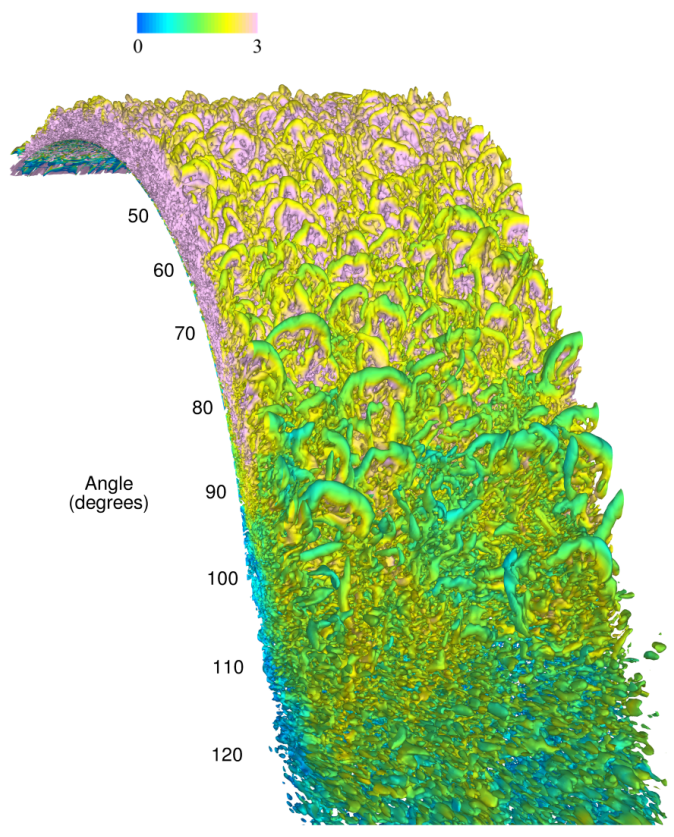

(b) Iso-surfaces of second invariant of velocity gradient tensor, colored by the magnitude of velocity $\left(u_{i} u_{i}\right)^{1 / 2} / U_{r e f}$, extra-fine grid

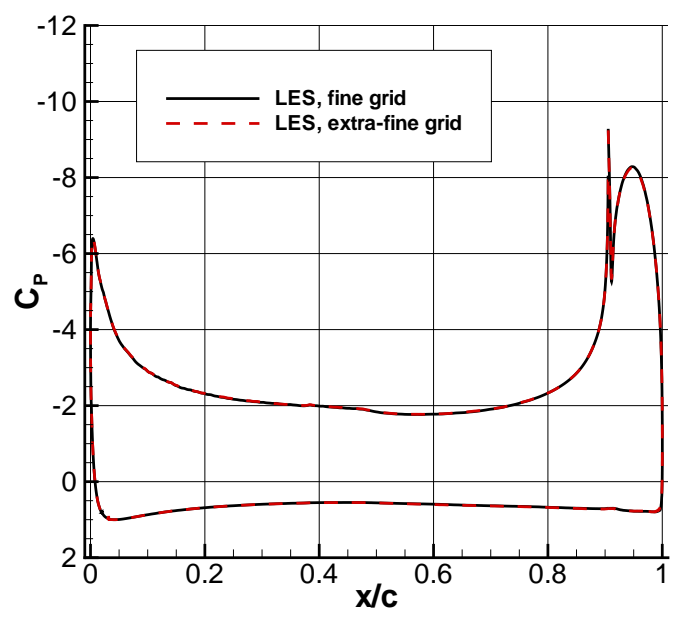

(c) Surface pressure coefficients

Figure 4. Effect of grid refinement on LES results, $M_{j}=0.64$. 

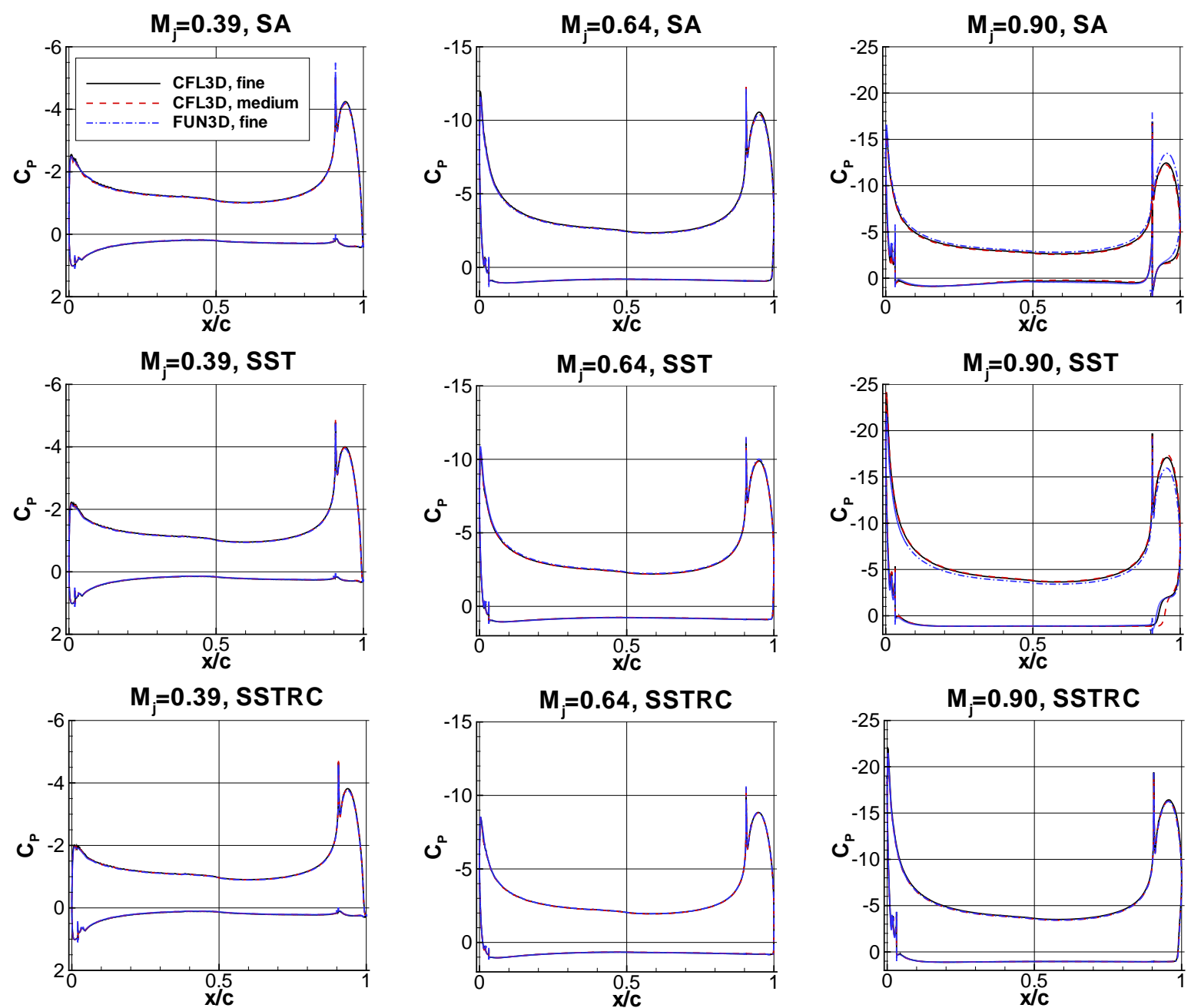

(a) CFL3D and FUN3D
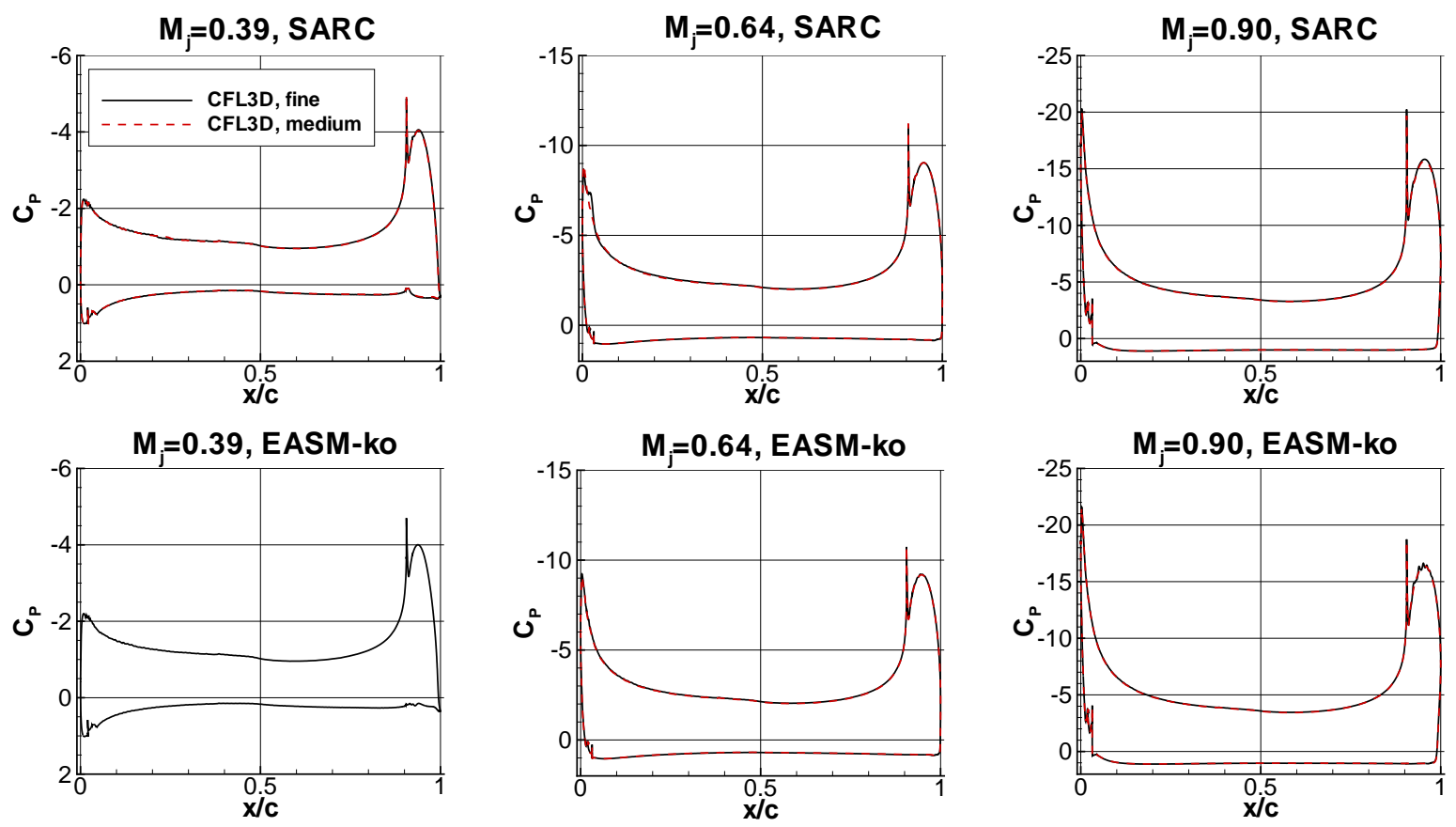

(b) CFL3D

Figure 5. Effect of code and grid refinement on RANS surface pressure coefficients. 


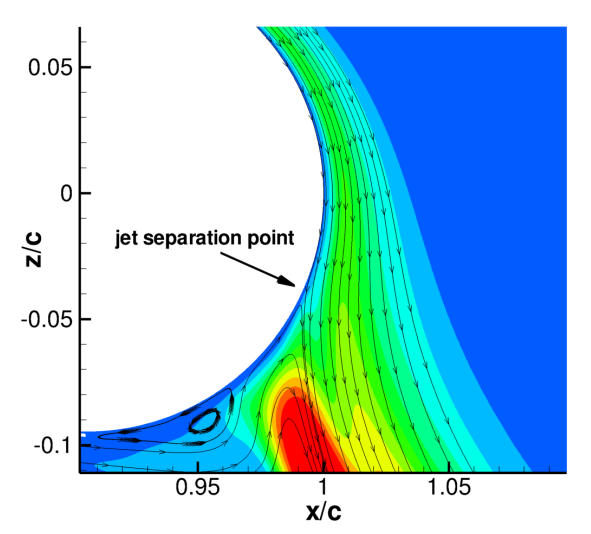

(a) Incompressible streamlines superimposed on eddy viscosity contours (arrow indicates jet separation location)

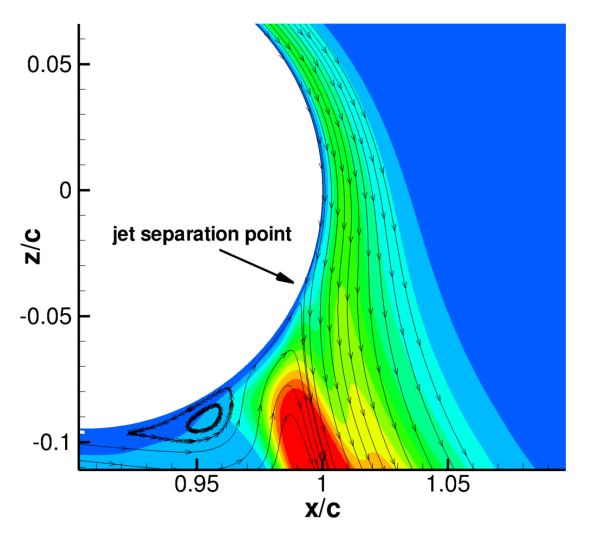

(b) Compressible streamlines superimposed on eddy viscosity contours (arrow indicates jet separation location)
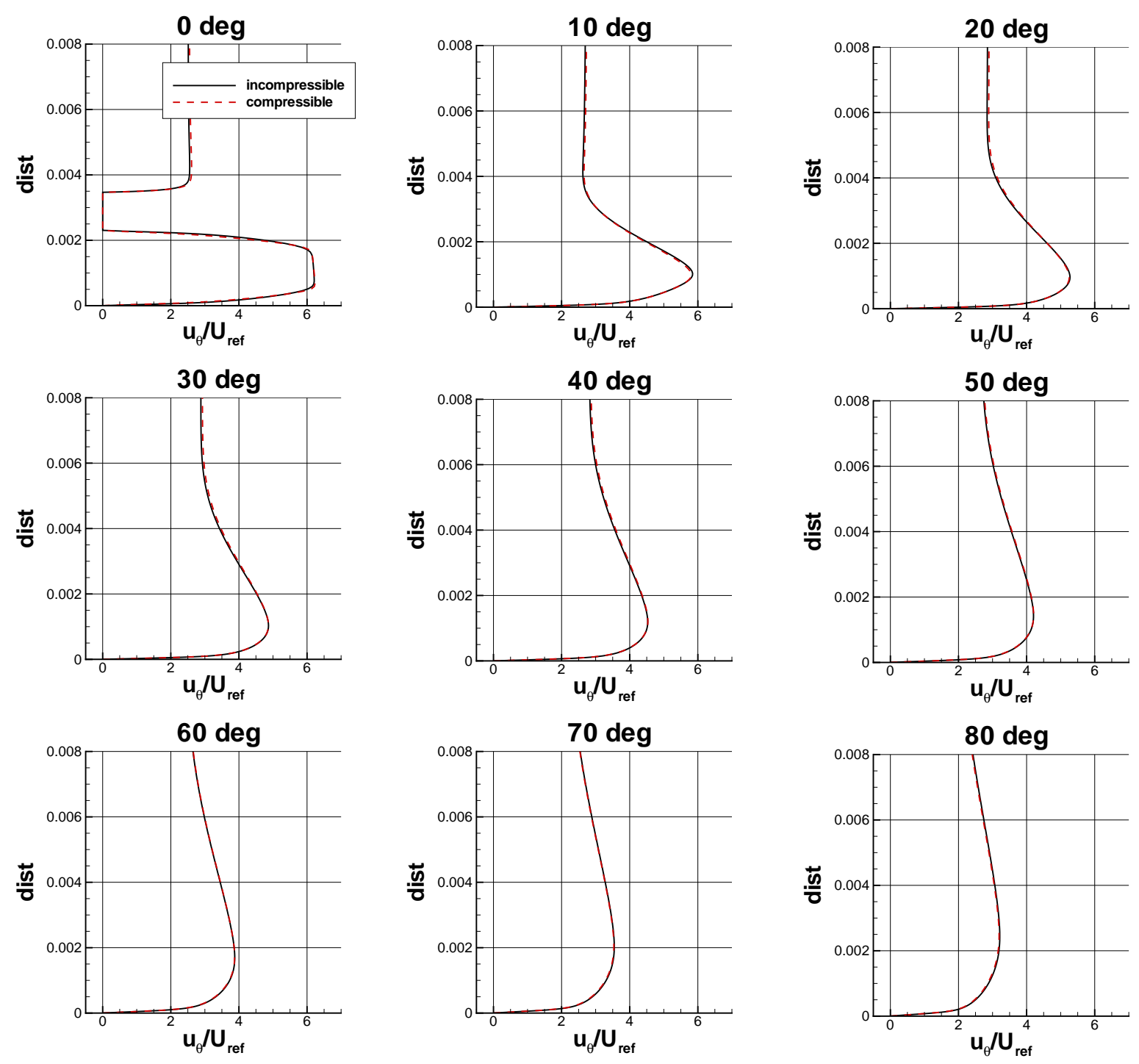

(c) Velocity profiles

Figure 6. Comparisons of incompressible and compressible results for $M_{j}=0.64$, FUN3D, SA turbulence model. 


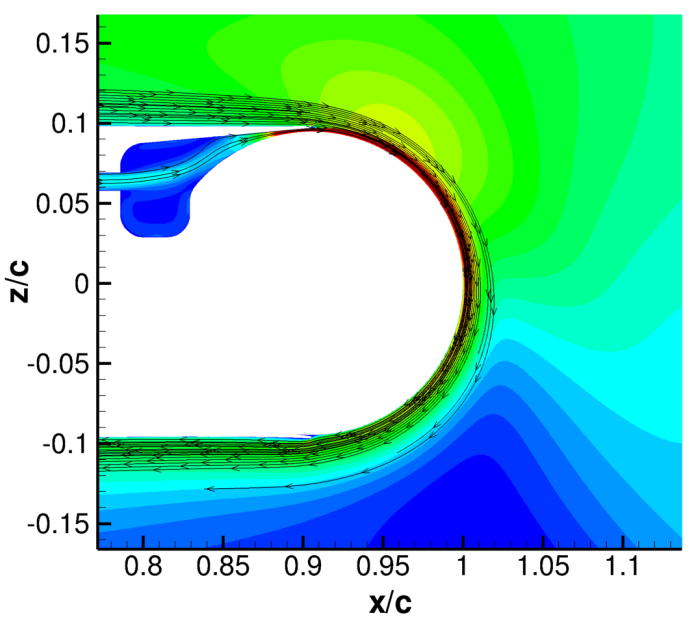

(a) $\mathrm{SA}$

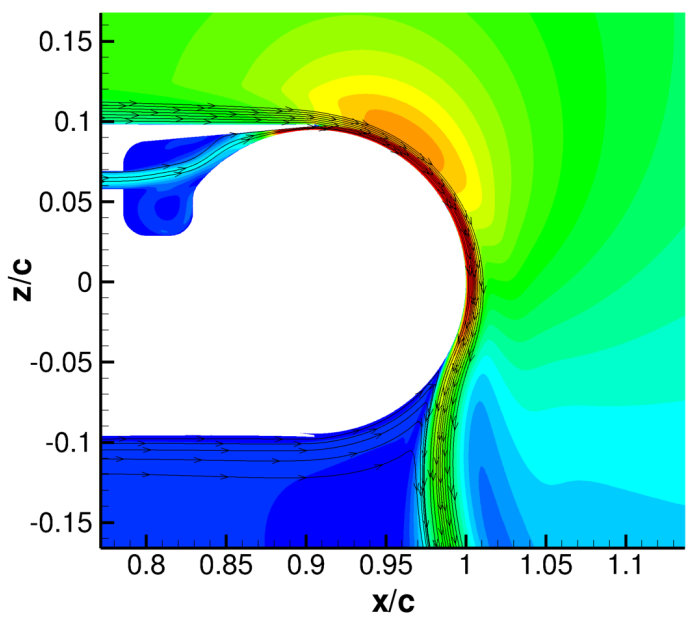

(c) SSTRC

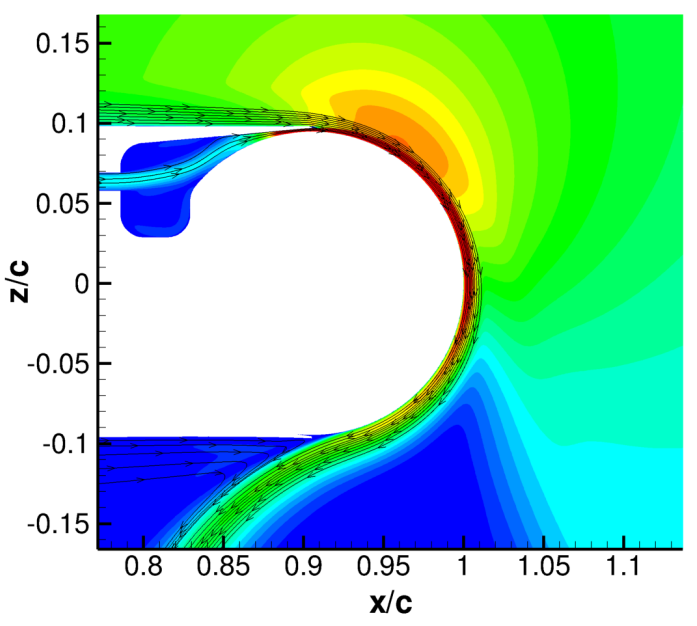

(b) SST

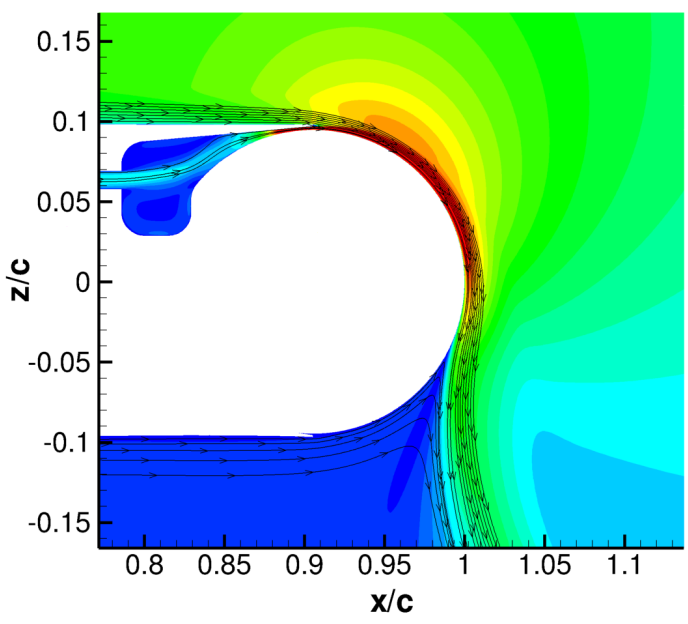

(d) SARC

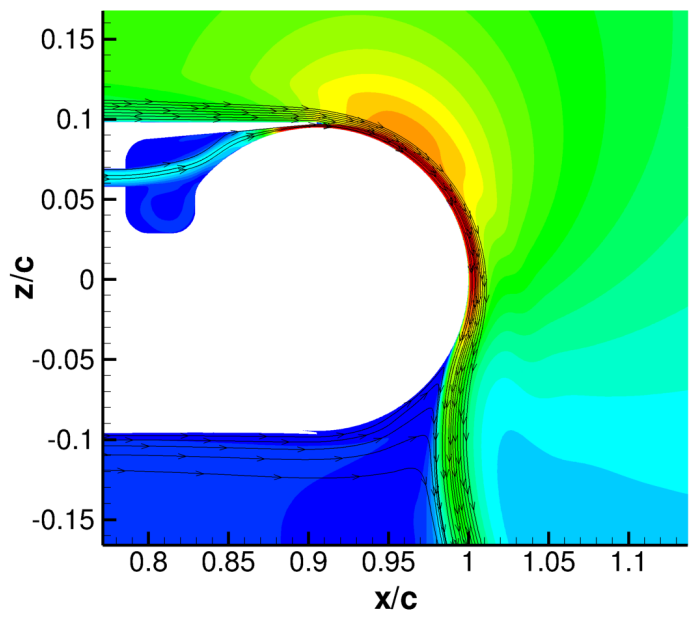

(e) EASM-ko

Figure 7. Streamlines (superimposed on Mach contours) for compressible RANS simulations, $M_{j}=0.90$, CFL3D. 


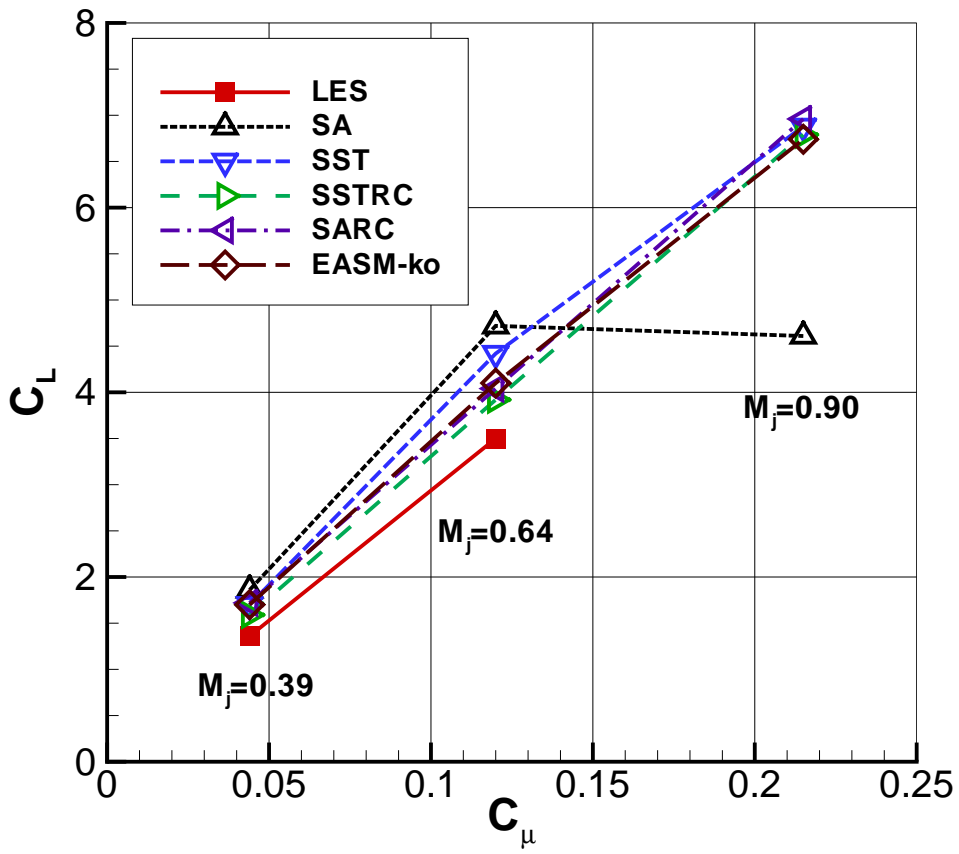

Figure 8. Lift coefficients as a function of blowing coefficient.

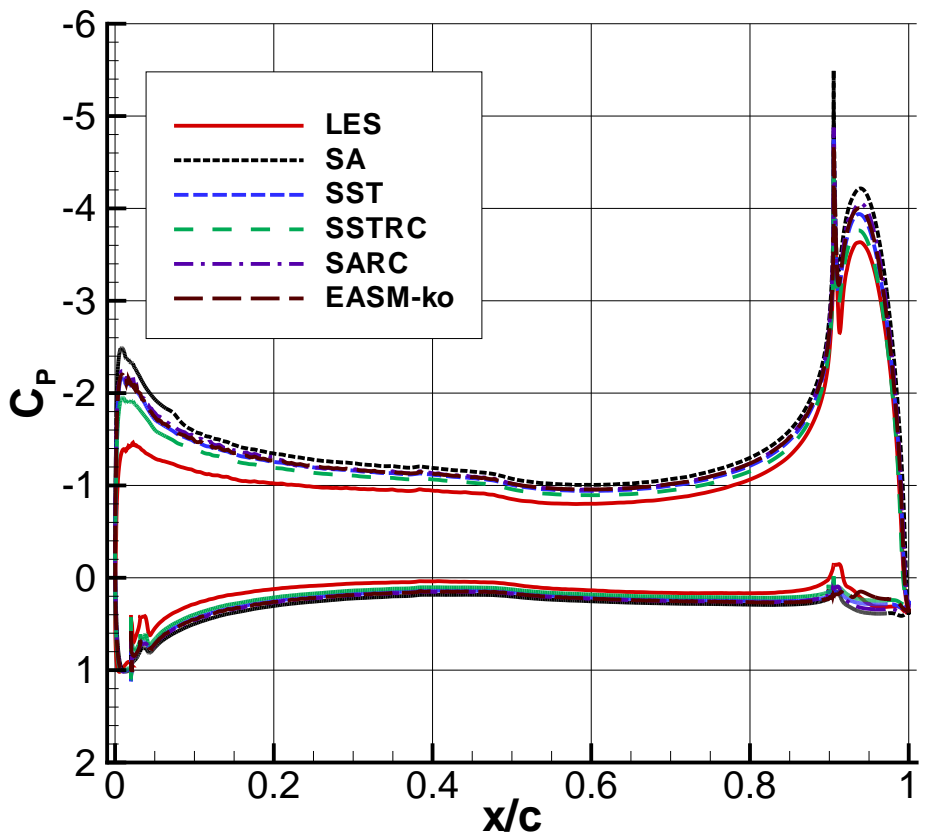

Figure 9. Surface pressure coefficients, $M_{j}=0.39$.

18 of 29 

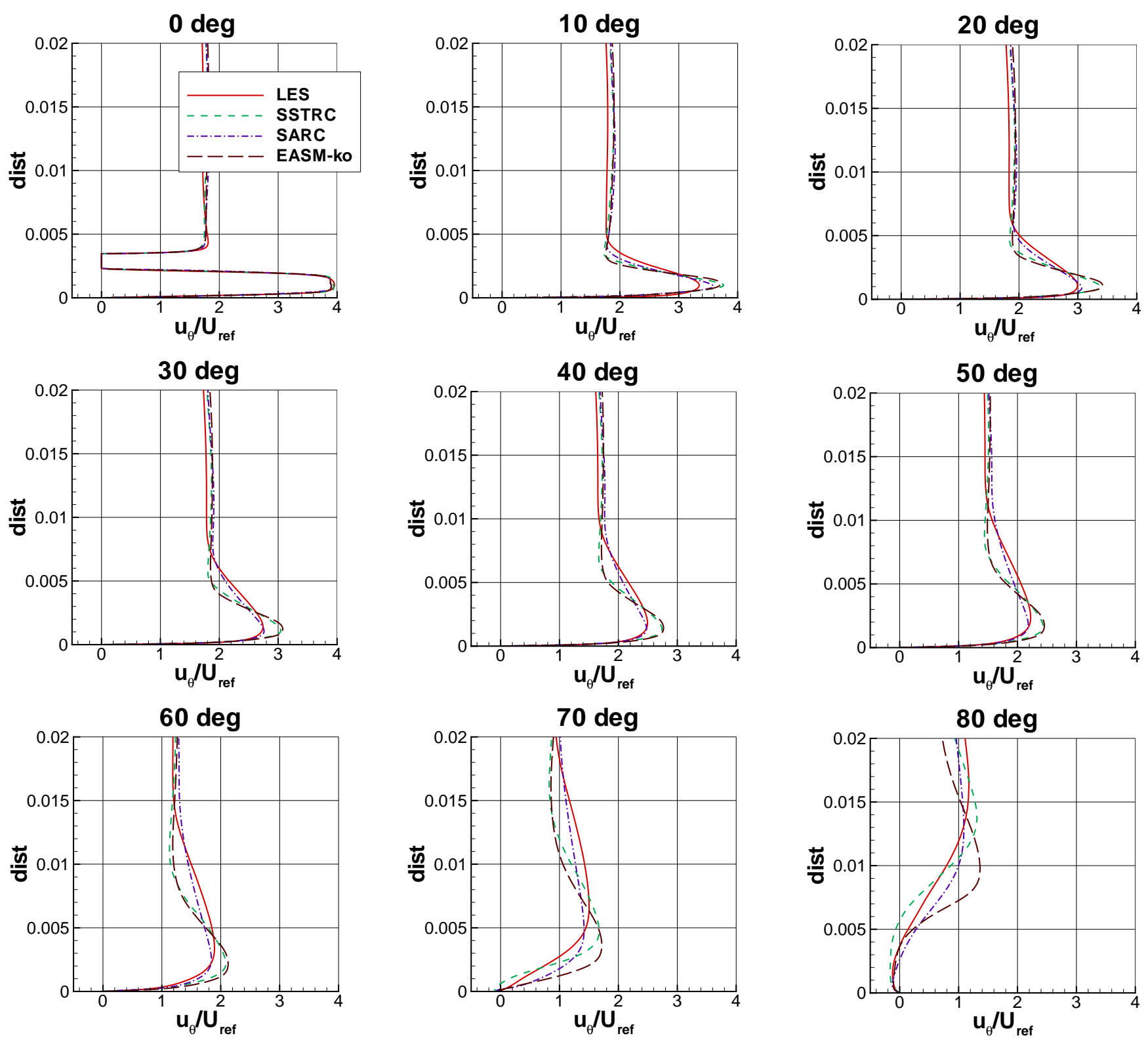

Figure 10. Velocity profiles, $M_{j}=0.39$. 

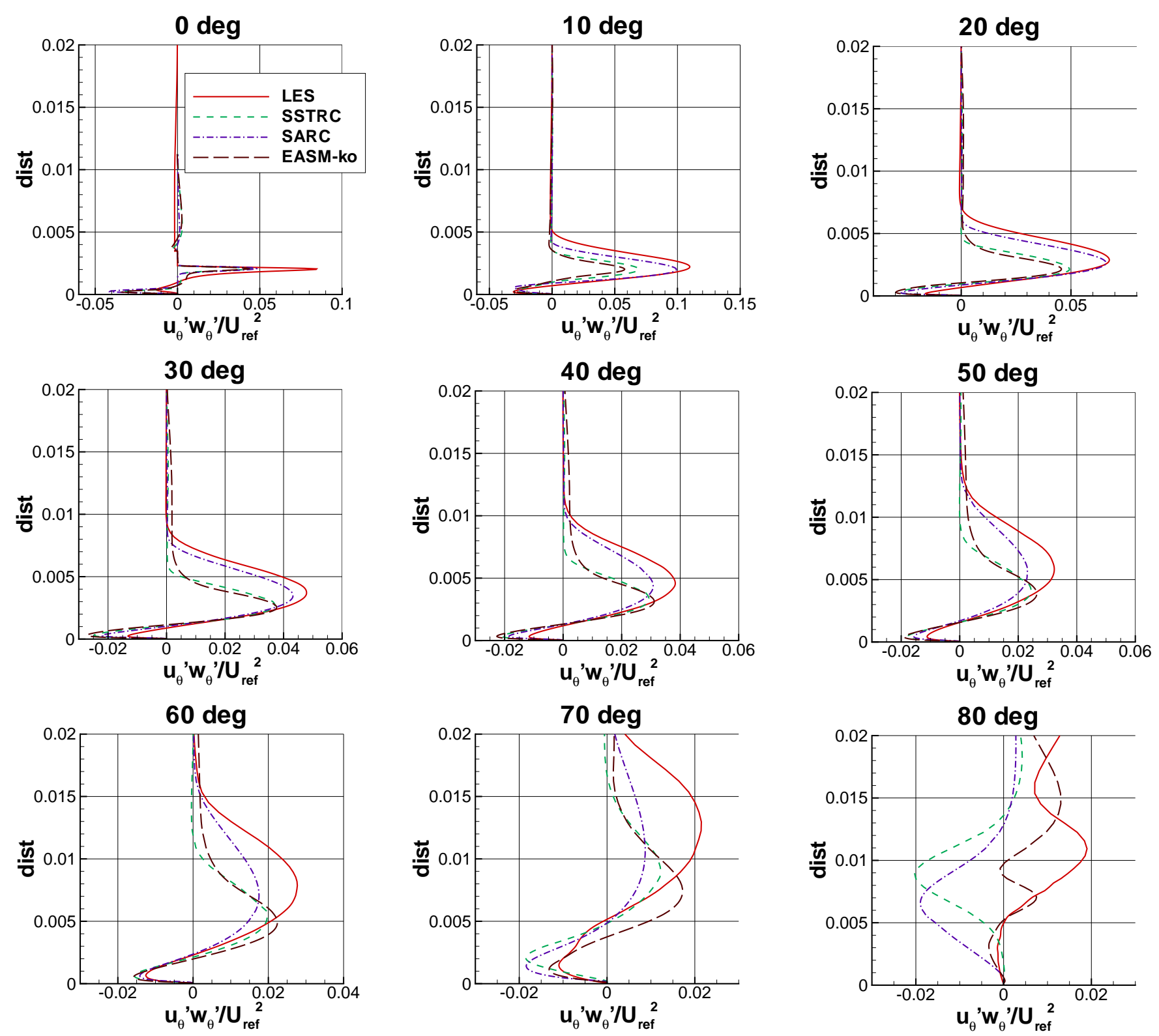

Figure 11. Turbulent $\overline{u_{\theta}^{\prime} w_{\theta}^{\prime}}$ profiles, $M_{j}=0.39$. 


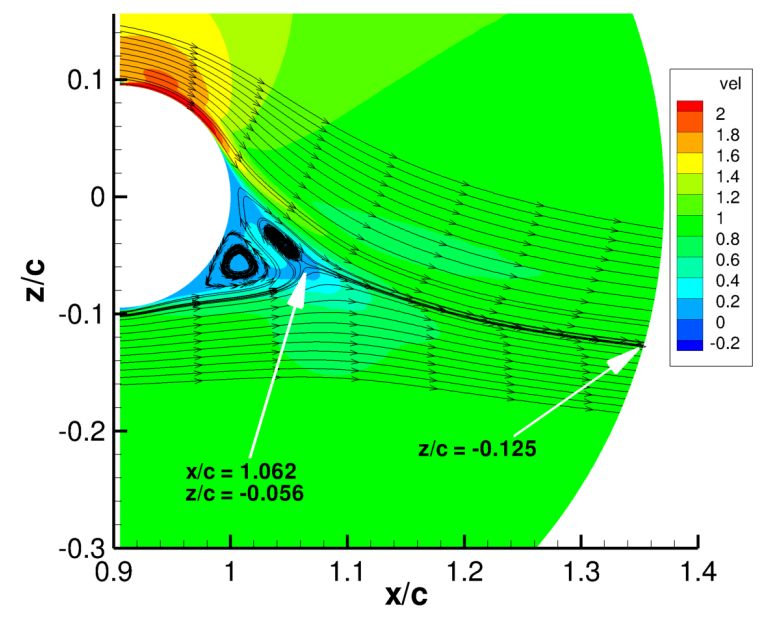

(a) LES

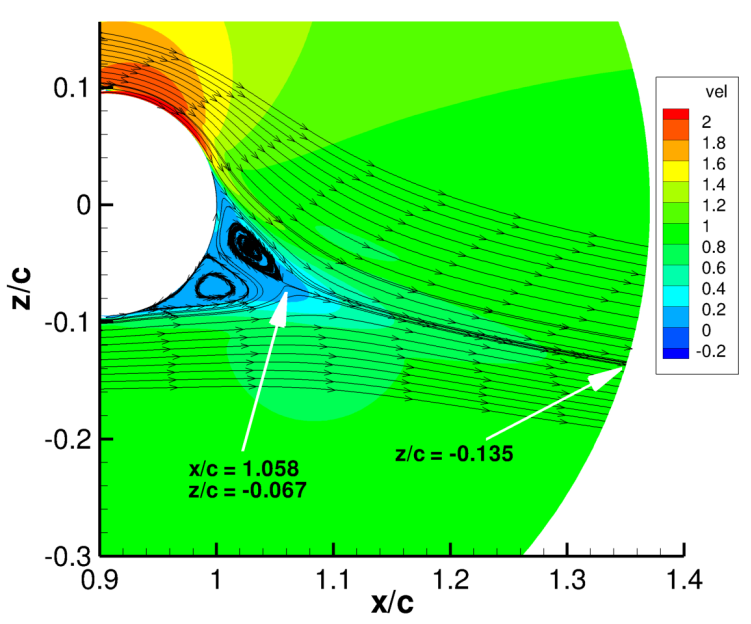

(c) SARC

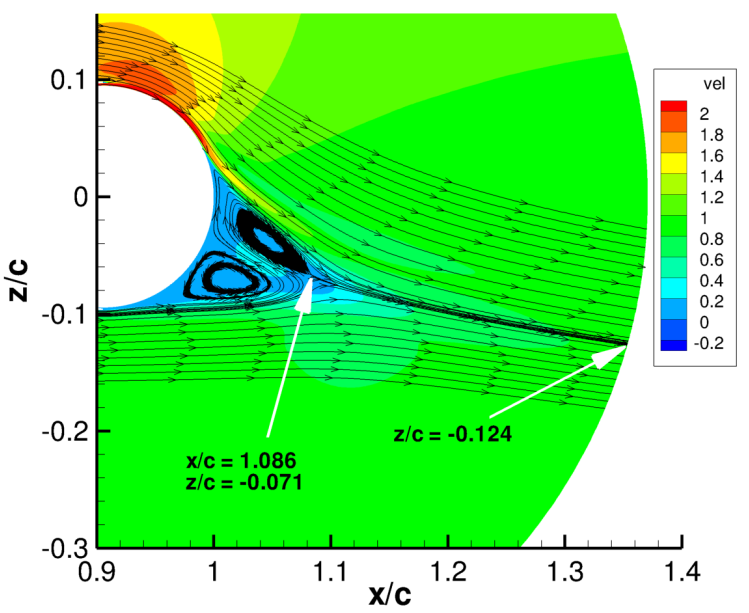

(b) SSTRC

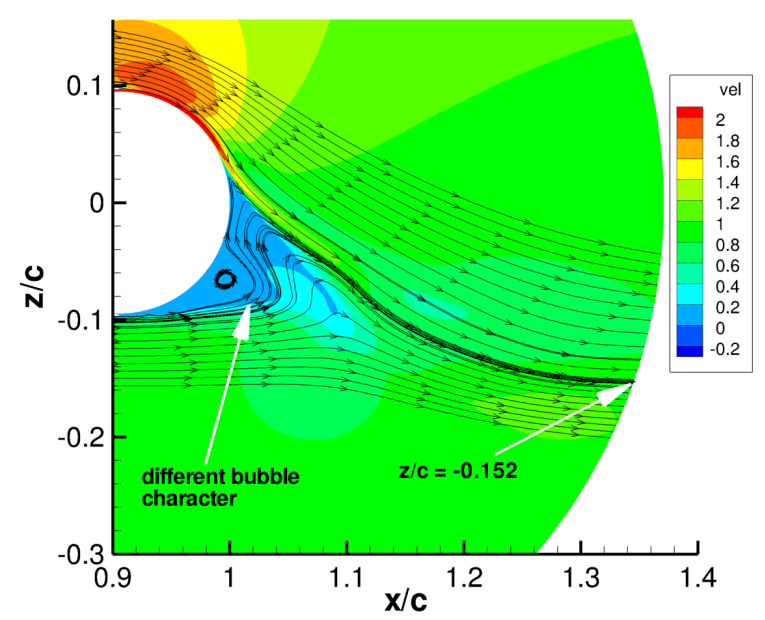

(d) EASM-ko

Figure 12. Streamlines near trailing edge (superimposed on velocity magnitude contours), $M_{j}=0.39$. 


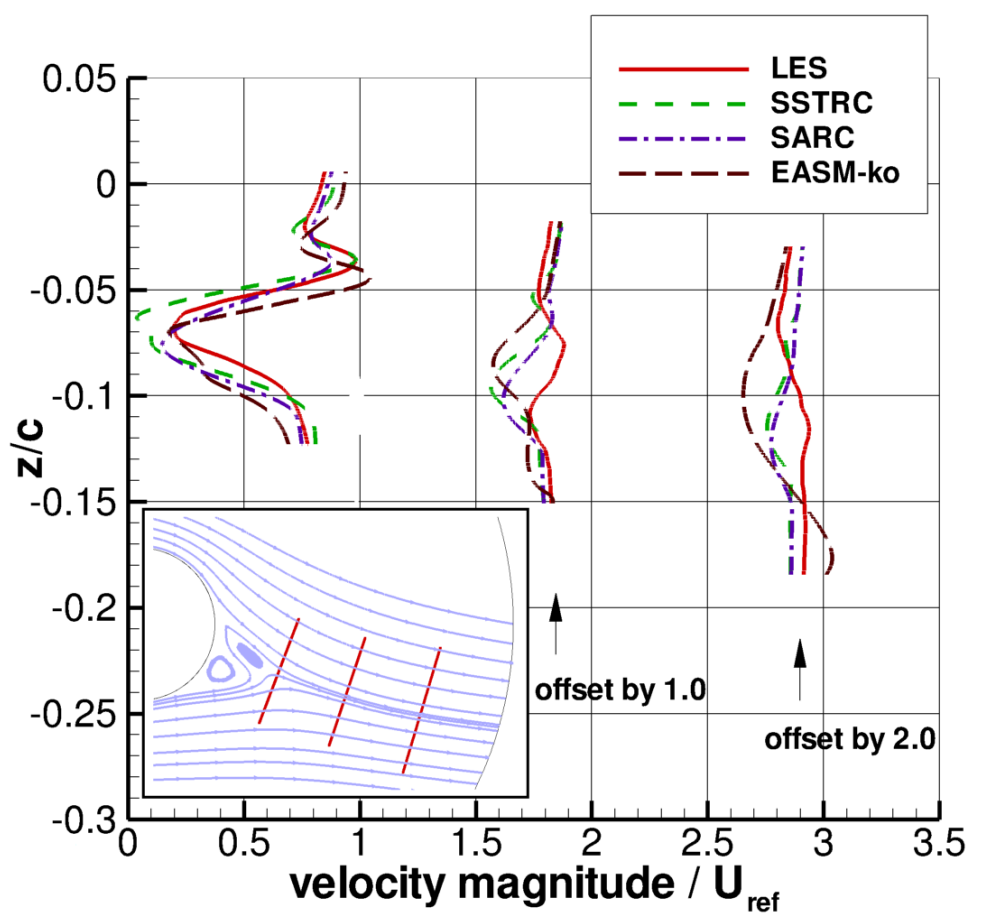

Figure 13. Comparison of jet/wake profiles, $M_{j}=0.39$.

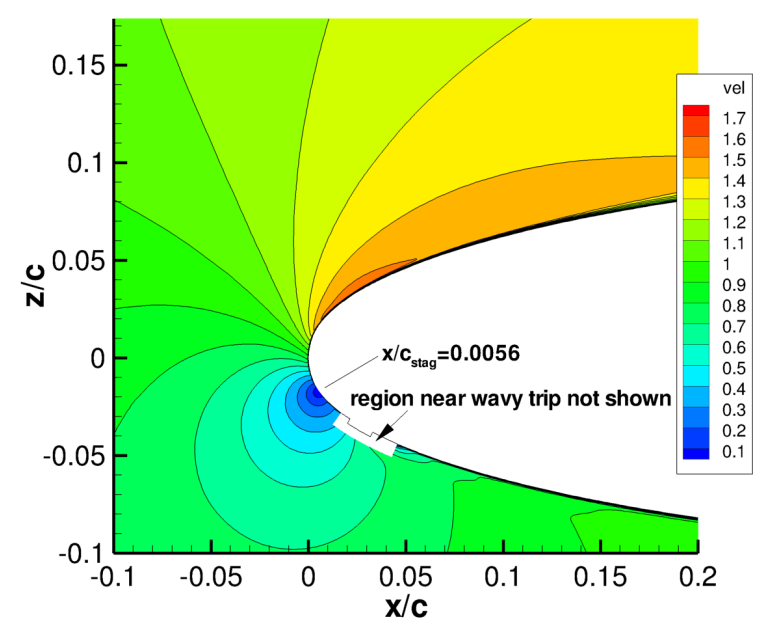

(a) LES

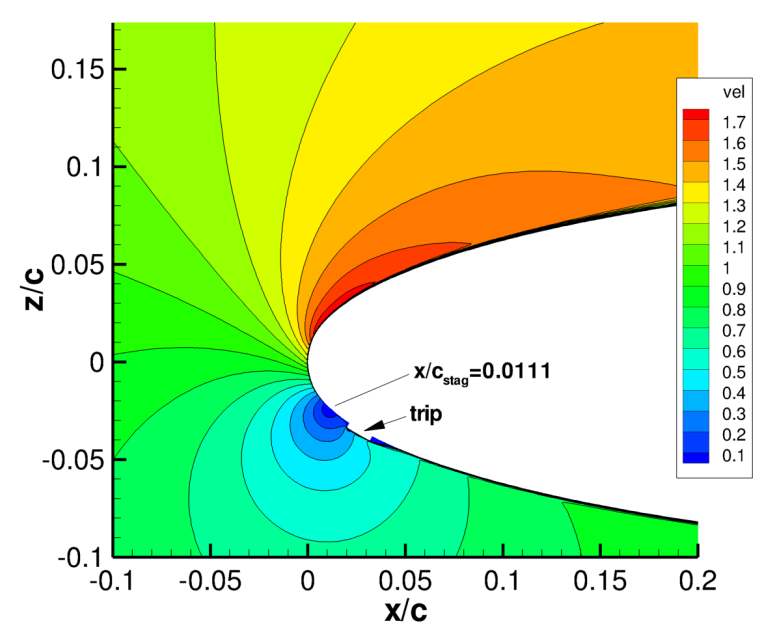

(b) SARC

Figure 14. Comparison of LES and RANS velocity magnitude contours near leading edge, $M_{j}=0.39$. 


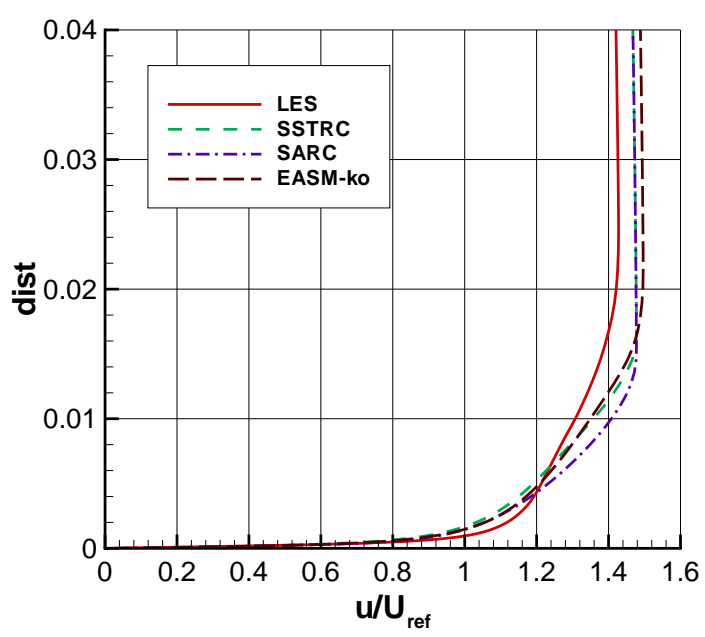

(a) Upper surface, velocity profiles

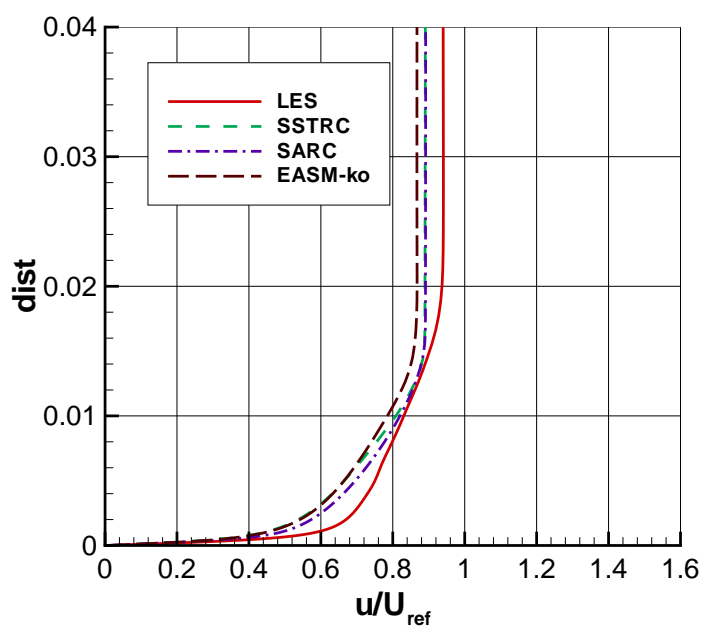

(c) Lower surface, velocity profiles

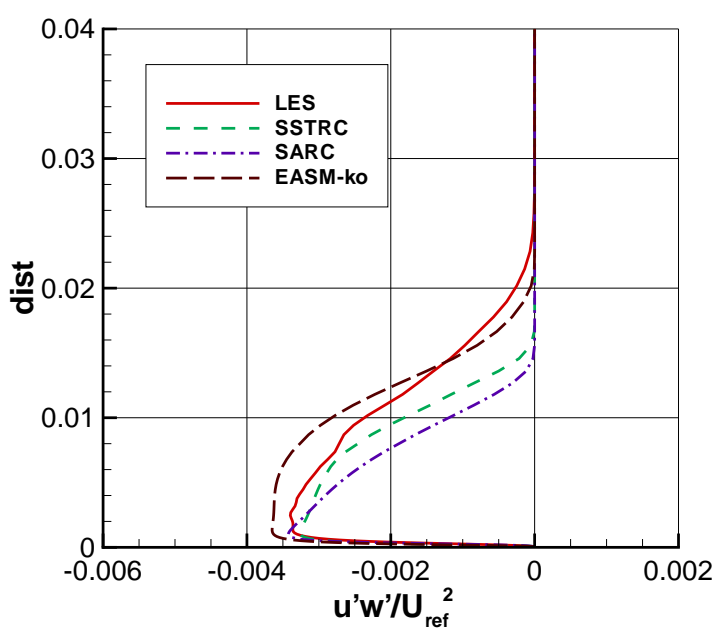

(b) Upper surface, turbulent profiles

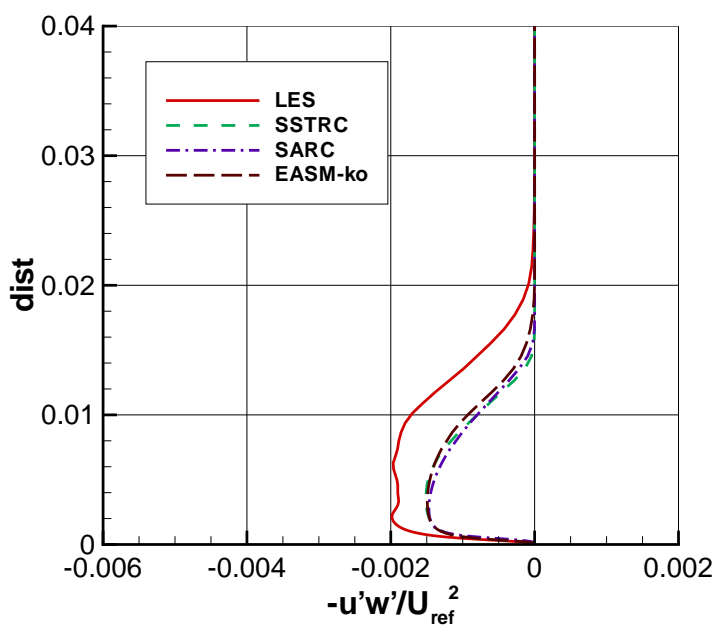

(d) Lower surface, turbulent profiles

Figure 15. Boundary layer profiles near $x / c=0.8$ on upper and lower surfaces, $M_{j}=0.39$. 


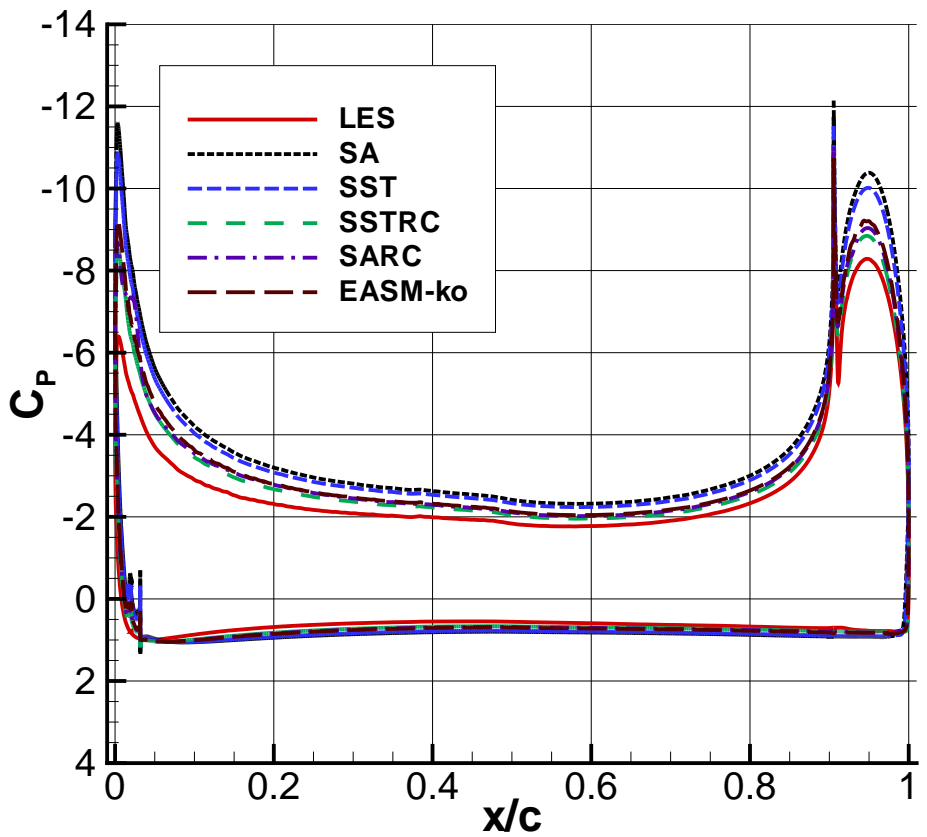

Figure 16. Surface pressure coefficients, $M_{j}=0.64$. 

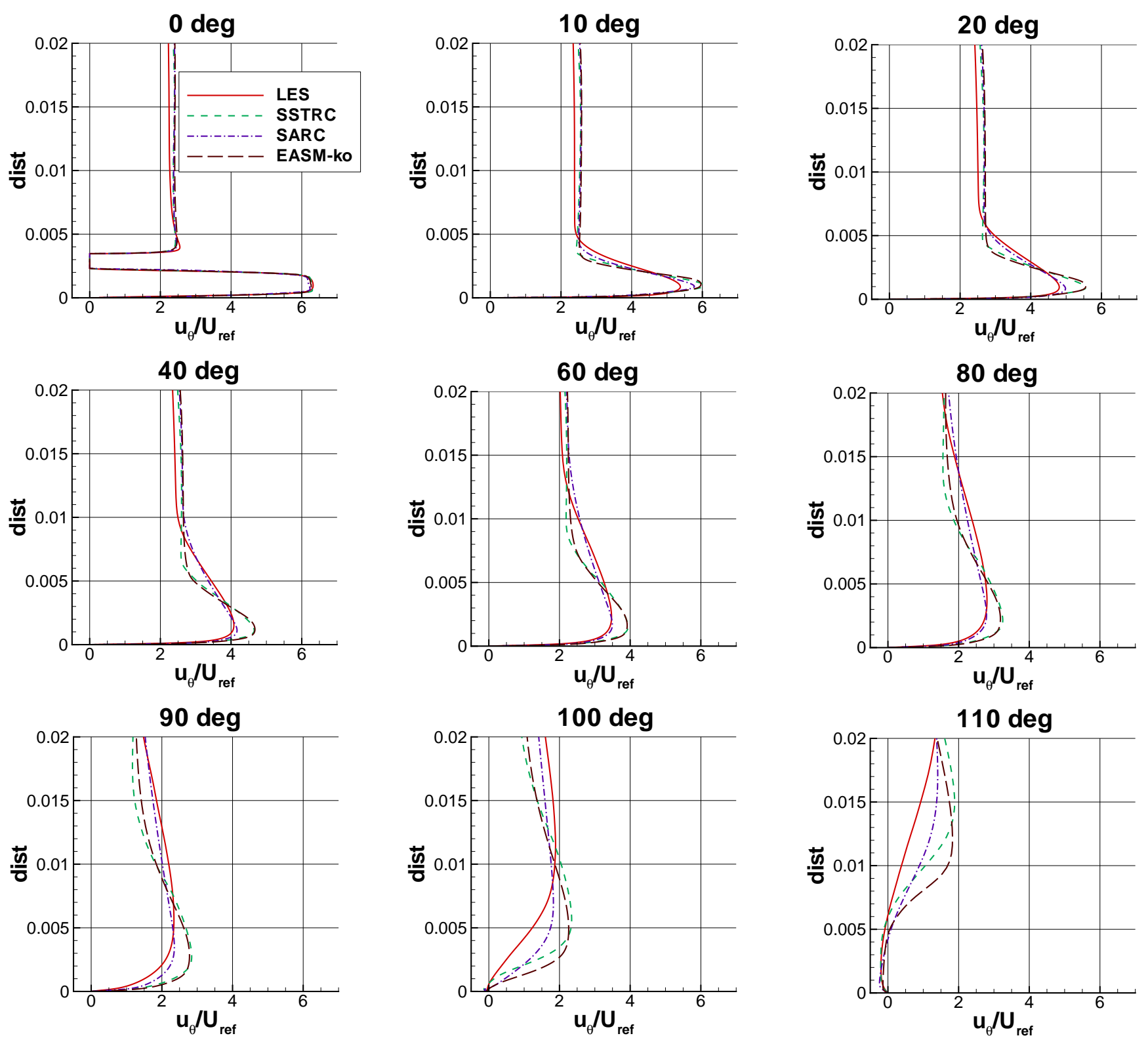

Figure 17. Velocity profiles, $M_{j}=0.64$. 

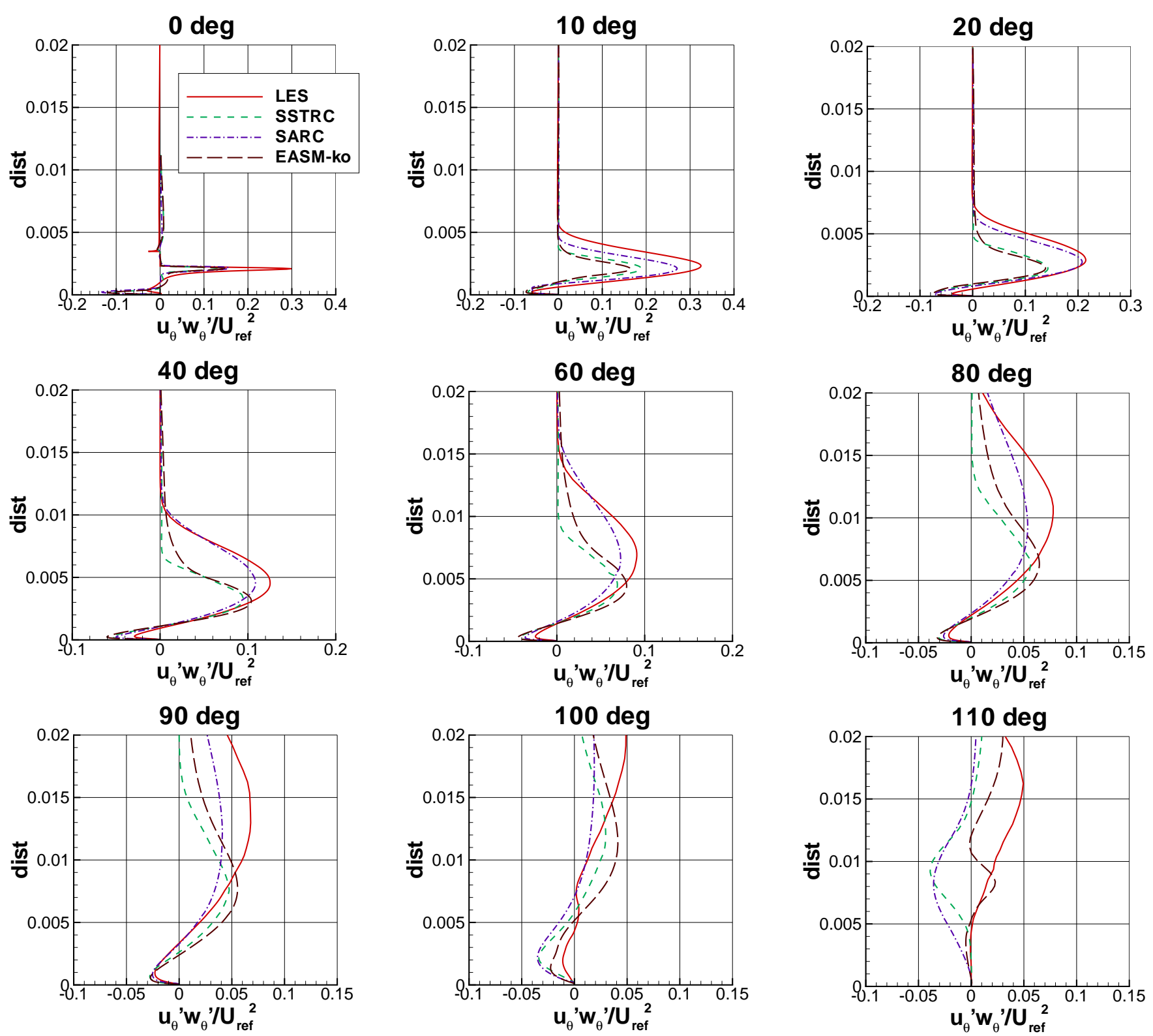

Figure 18. Turbulent $\overline{u_{\theta}^{\prime} w_{\theta}^{\prime}}$ profiles, $M_{j}=0.64$. 


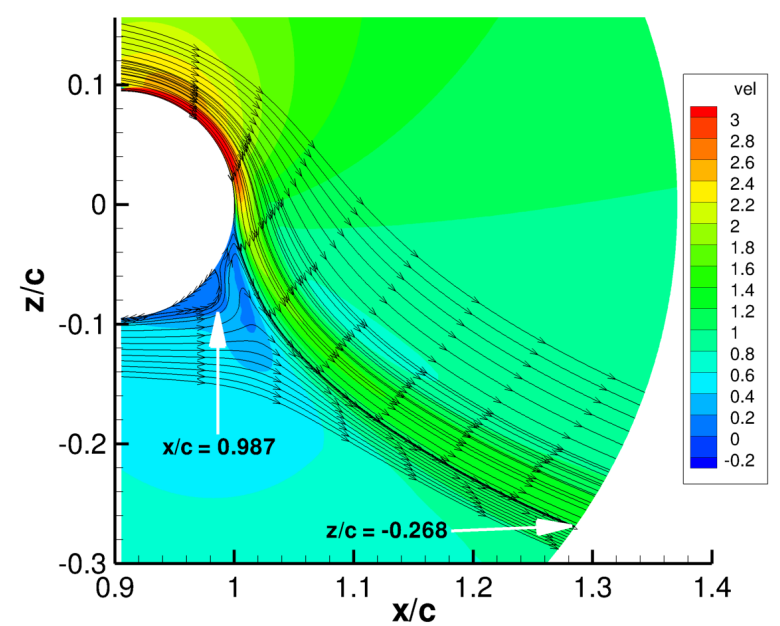

(a) LES

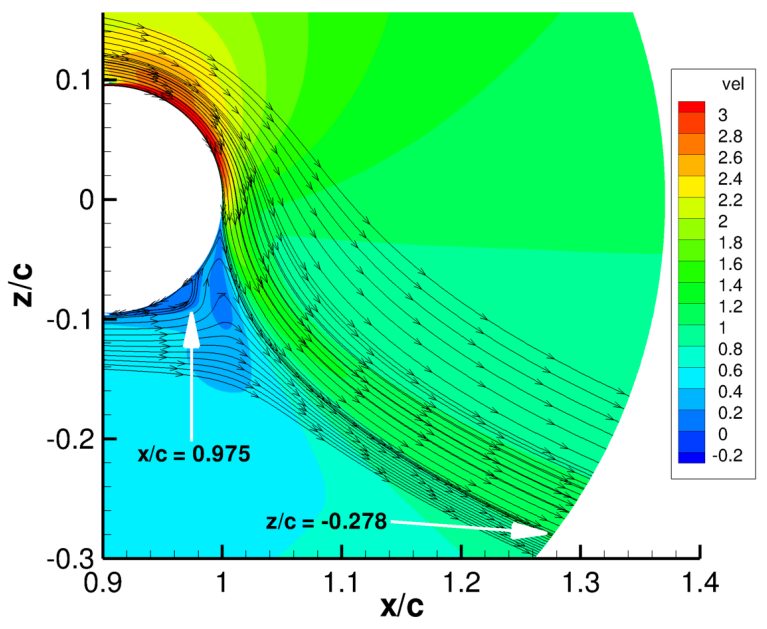

(c) SARC

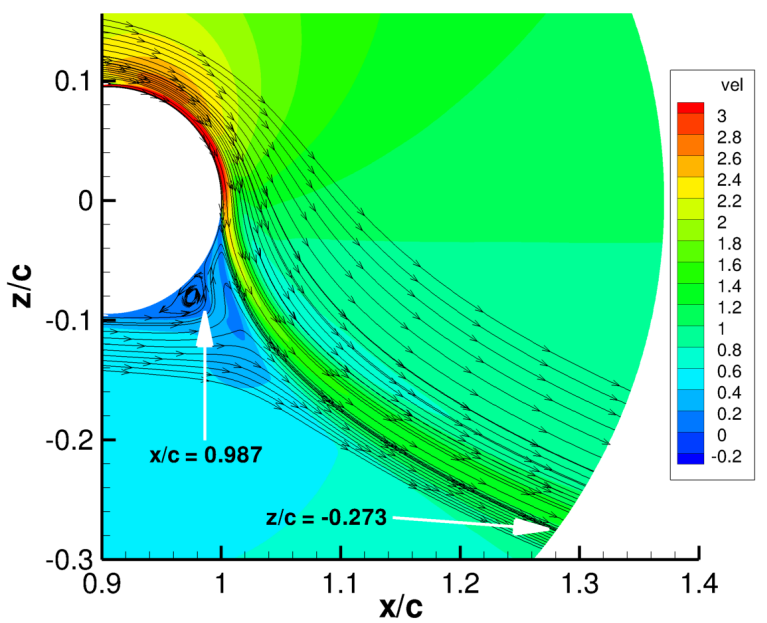

(b) SSTRC

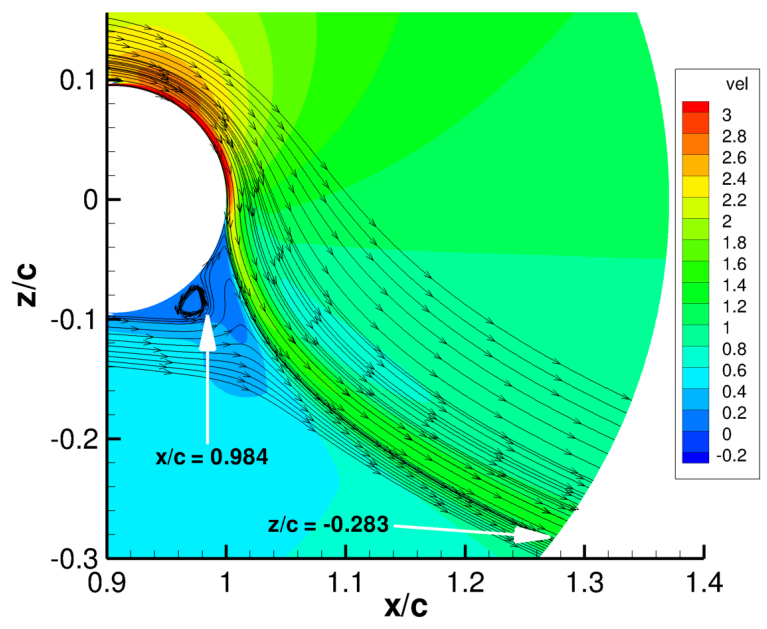

(d) EASM-ko

Figure 19. Streamlines near trailing edge (superimposed on velocity magnitude contours), $M_{j}=0.64$. 


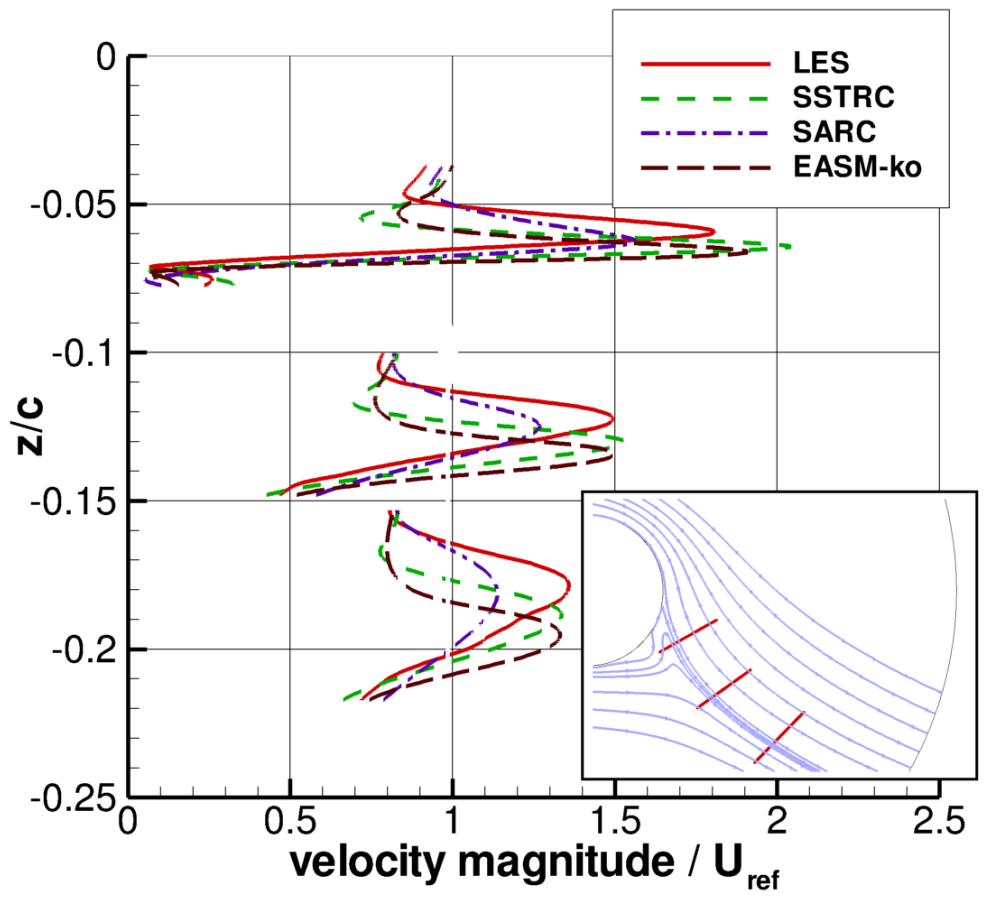

Figure 20. Comparison of jet/wake profiles, $M_{j}=0.64$.

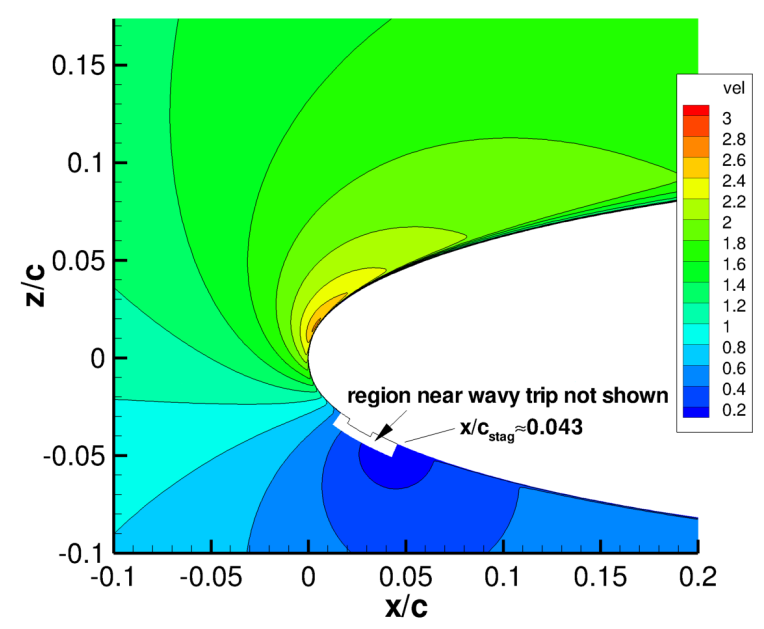

(a) LES

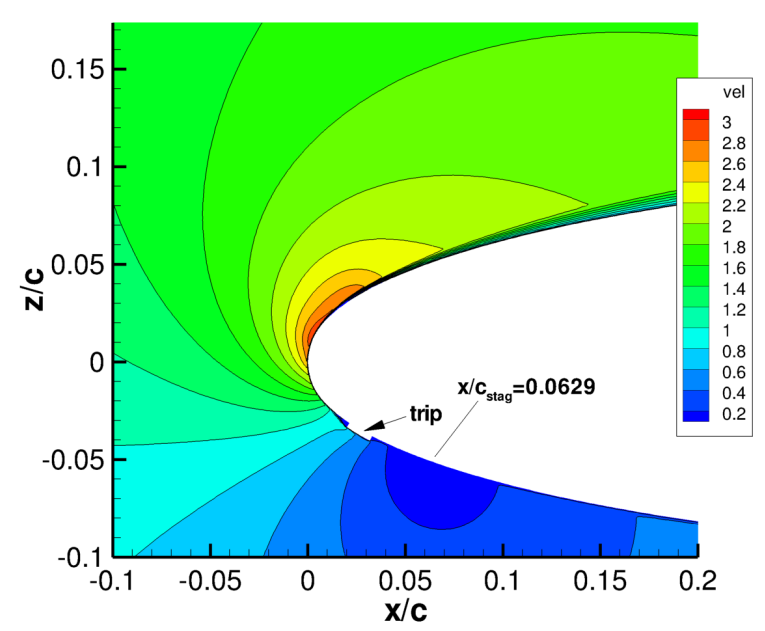

(b) SARC

Figure 21. Comparison of LES and RANS velocity magnitude contours near leading edge, $M_{j}=0.64$. 


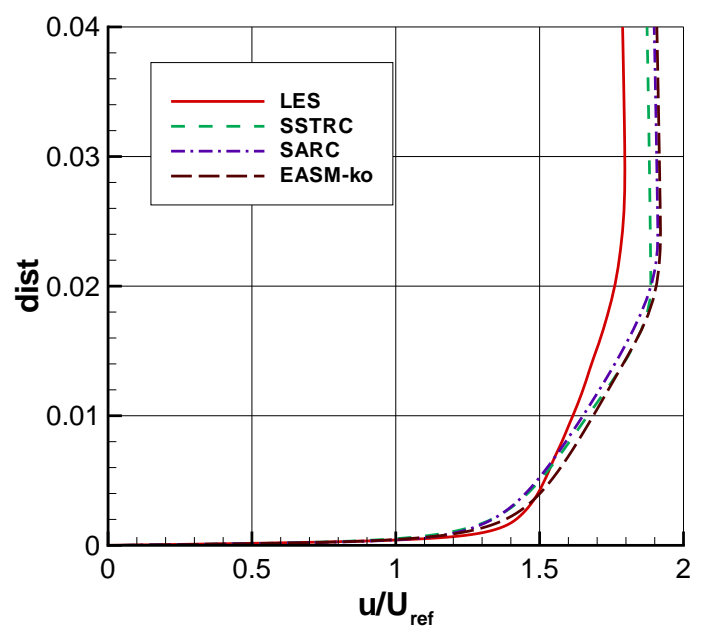

(a) Upper surface, velocity profiles

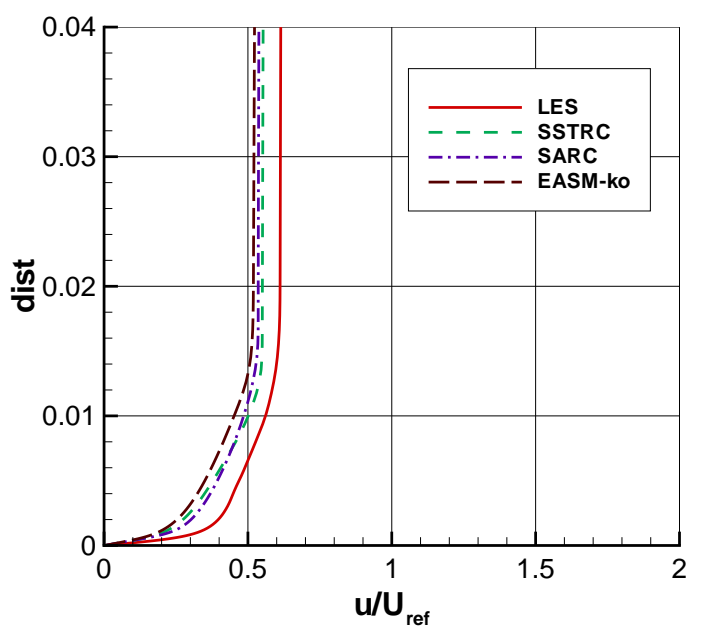

(c) Lower surface, velocity profiles

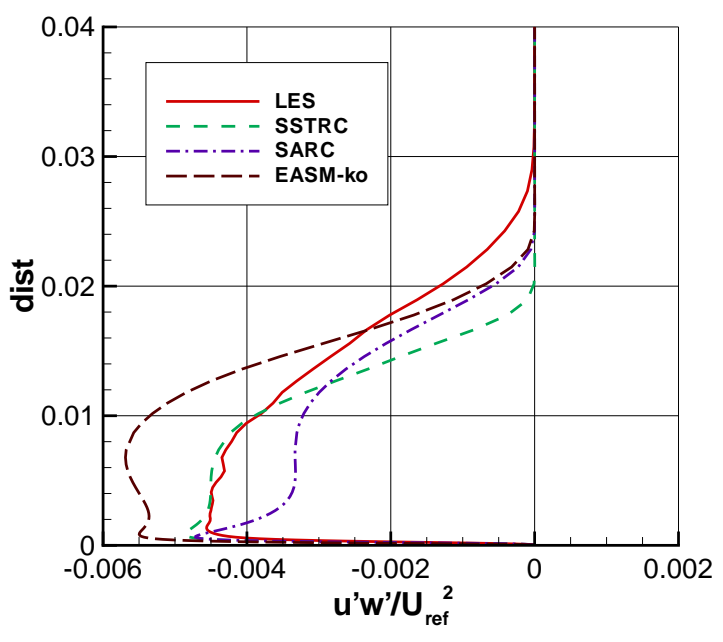

(b) Upper surface, turbulent profiles

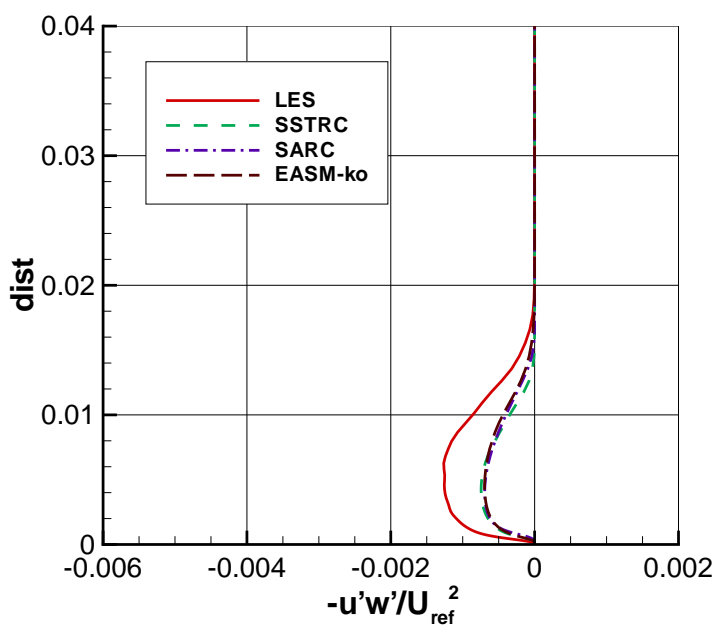

(d) Lower surface, turbulent profiles

Figure 22. Boundary layer profiles near $x / c=0.8$ on upper and lower surfaces, $M_{j}=0.64$. 